NASA/TP-2001-211412

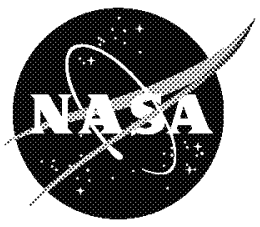

\title{
Development of a Gas-Fed Pulse Detonation Research Engine
}

R.J. Litchford

Marshall Space Flight Center, Marshall Space Flight Center, Alabama 


\section{The NASA STI Program Office....in Profile}

Since its founding, NASA has been dedicated to the advancement of aeronautics and space science. The NASA Scientific and Technical Information (STI) Program Office plays a key part in helping NASA maintain this important role.

The NASA STI Program Office is operated by Langley Research Center, the lead center for NASA's scientific and technical information. The NASA STI Program Office provides access to the NASA STI Database, the largest collection of aeronautical and space science STI in the world. The Program Office is also NASA's institutional mechanism for disseminating the results of its research and development activities. These results are published by NASA in the NASA STI Report Series, which includes the following report types:

- TECHNICAL PUBLICATION. Reports of completed research or a major significant phase of research that present the results of NASA programs and include extensive data or theoretical analysis. Includes compilations of significant scientific and technical data and information deemed to be of continuing reference value. NASA's counterpart of peer-reviewed formal professional papers but has less stringent limitations on manuscript length and extent of graphic presentations.

- TECHNICAL MEMORANDUM. Scientific and technical findings that are preliminary or of specialized interest, e.g., quick release reports, working papers, and bibliographies that contain minimal annotation. Does not contain extensive analysis.

- CONTRACTOR REPORT. Scientific and technical findings by NASA-sponsored contractors and grantees.
- CONFERENCE PUBLICATION. Collected papers from scientific and technical conferences, symposia, seminars, or other meetings sponsored or cosponsored by NASA.

- SPECIAL PUBLICATION. Scientific, technical, or historical information from NASA programs, projects, and mission, often concerned with subjects having substantial public interest.

- TECHNICAL TRANSLATION. English-language translations of foreign scientific and technical material pertinent to NASA's mission.

Specialized services that complement the STI Program Office's diverse offerings include creating custom thesauri, building customized databases, organizing and publishing research results...even providing videos.

For more information about the NASA STI Program Office, see the following:

- Access the NASA STI Program Home Page at http://www.sti.nasa.gov

- E-mail your question via the Internet to help@sti.nasa.gov

- Fax your question to the NASA Access Help Desk at (301) 621-0134

- Telephone the NASA Access Help Desk at (301) 621-0390

- Write to: NASA Access Help Desk NASA Center for AeroSpace Information 7121 Standard Drive Hanover, MD 21076-1320 (301)621-0390 


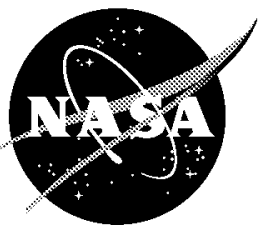

\section{Development of a Gas-Fed Pulse Detonation Research Engine}

R.J. Litchford

Marshall Space Flight Center, Marshall Space Flight Center, Alabama

National Aeronautics and

Space Administration

Marshall Space Flight Center • MSFC, Alabama 35812 


\section{Acknowledgments}

This work was sponsored by the Third Generation Space Transportation Project Office (John Hutt, Project Manager), Advanced Space Transportation Program, Marshall Space Flight Center, National Aeronautics and Space Administration. The NASA Principal Investigator was Ron J. Litchford, Project Scientist, Space Transportation Research Project Office,

TD15/ASTP. The author also wishes to acknowledge the excellent engineering and test support provided by Bryan R. Thompson of TMET, Winchester, TN.

Available from:

NASA Center for AeroSpace Information

7121 Standard Drive

Hanover, MD 21076-1320

(301) 621-0390
National Technical Information Service 5285 Port Royal Road Springfield, VA 22161

(703) $487-4650$ 


\section{TABLE OF CONTENTS}

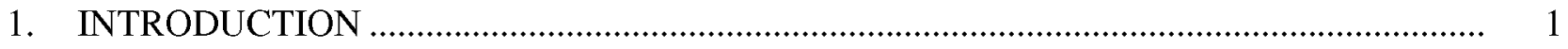

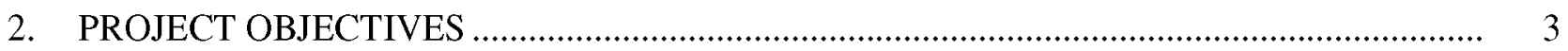

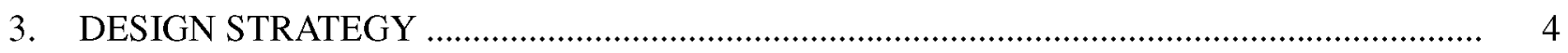

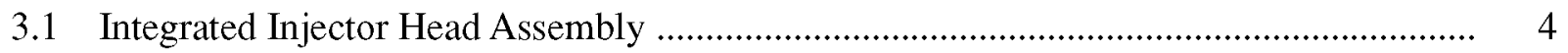

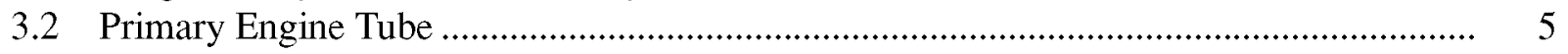

3.3 Ignition and Valve Control Circuits .............................................................................. 5

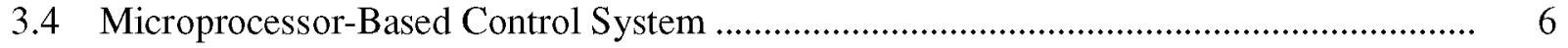

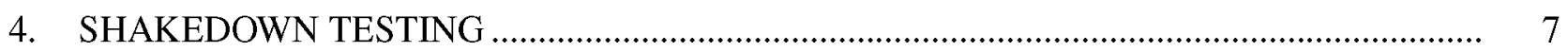

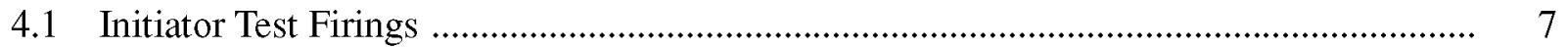

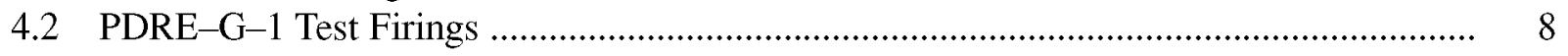

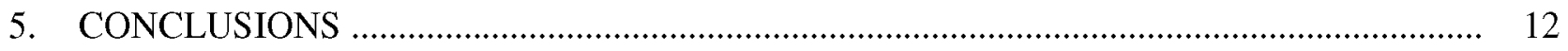

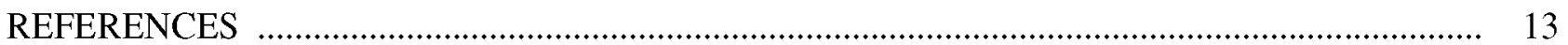




\section{LIST OF FIGURES}

1. Schematic of integrated injector head assembly. The initiator tube containing the primary coaxial injector is inserted through the center of the injector head face. Four auxiliary coaxial injectors are distributed at $90^{\circ}$ intervals around the central initiator tube

2. Photograph of integrated injector head assembly in preparation for preliminary shakedown testing (side view)

3. Photograph of integrated injector head assembly in preparation for preliminary shakedown testing (injector face view)

4. Schematic of the igniter control circuit using fiber optic coupling from a TTL optical transmitter to a TTL optical receiver

5. Schematic of the propellant valve control circuit using fiber optic coupling from

a TTL optical transmitter to a TTL optical receiver

6. Microprocessor control signals acquired at the output of the TTL optical receivers during a $40-\mathrm{Hz}$ initiator shakedown test

7. Theoretical C-J detonation characteristics as a function of $\mathrm{H}_{2}$ volume fraction

8. Theoretical flame front trajectories on the position-time wave diagram

9. Cross section of the mild steel initiator model with pressure sensor ports (dimensions in centimeters)

10. Measured pressure waveforms in the initiator tube with smooth bore. Indicated flame front velocity was $540 \mathrm{~m} / \mathrm{sec}$

11. Illustration of Schelkin spiral and its effect on turbulent mixing and flame acceleration

12. Measured pressure waveforms in the initiator tube with Schelkin spiral No. 1. Indicated flame front velocity was $1,400 \mathrm{~m} / \mathrm{sec}$

13. Measured pressure waveforms in the initiator tube with Schelkin spiral No. 2. Indicated flame front velocity was $2,400 \mathrm{~m} / \mathrm{sec}$ 


\section{LIST OF FIGURES (continued)}

14. Schematic of PDRE-G-1 research engine on the test stand. Sensor port locations and indices are indicated

15. Measured pressure waveforms in the primary tube with smooth bore. Indicated flame front velocity was $505 \mathrm{~m} / \mathrm{sec}$

16. Measured pressure waveforms in the primary tube with Schelkin spiral installed along its entire length. Indicated flame front velocity was $2,200 \mathrm{~m} / \mathrm{sec}$

17. Measured pressure waveform distribution in the primary tube with Schelkin spiral installed along its entire length

18. Idealized PDRE cycle processes: (1) Detonation initiation; (2) propagation of detonation wave through chamber; (3) propagation of rarefaction wave from tube exit to tube head; (4) tube blowdown; (5) chamber exhausted to atmospheric pressure; and (6) injection of fresh propellant mixture

19. Idealized position-time wave diagram for PDRE blowdown process

20. Idealized PDRE tube head pressure for a simple straight tube configuration

21. Long exposure photograph of the exhaust plume from the PDRE-G-1 engine illustrating the firing characteristics for a filled tube condition. Obtained during a night firing with hydrogen/oxygen propellants

22. Long exposure photograph of the exhaust plume from the PDRE-G-1 engine illustrating the firing characteristics for an underfilled tube condition. Obtained during a night firing with hydrogen/oxygen propellants

23. Time-resolved PDRE-G-1 engine thrust profiles for filled and underfilled tube conditions 


\section{LIST OF ACRONYMS AND SYMBOLS}

$\begin{array}{ll}\text { AFB } & \text { Air Force Base } \\ \text { C-J } & \text { Chapman-Jouget (detonation condition) } \\ \text { CDI } & \text { capacitive discharge ignition } \\ \text { CFD } & \text { computational fluid dynamics } \\ \text { DDT } & \text { deflagration-to-detonation transition } \\ \mathrm{H}_{2} & \text { molecular hydrogen } \\ I_{s p} & \text { specific impulse } \\ \text { MSFC } & \text { Marshall Space Flight Center } \\ \mathrm{O}_{2} & \text { molecular oxygen } \\ \text { PC } & \text { personal computer } \\ \text { PDE } & \text { pulse detonation engine } \\ \text { PDRE } & \text { pulse detonation rocket engine } \\ \text { PDRE-G-1 } & \text { pulse detonation research engine (gas-fed series, model No. 1) } \\ \text { TTL } & \text { transistor-transistor logic }\end{array}$




\section{NOMENCLATURE}

$\begin{array}{ll}c_{3} & \text { speed of sound in burned gas } \\ E_{c} & \text { critical detonation initiation energy } \\ E_{i g n} & \text { ignition energy } \\ L_{C} & \text { chamber length } \\ L_{D D T} & \text { deflagration-to-detonation transition length } \\ p & \text { pressure } \\ p_{1} & \text { initial pressure in unburned mixture } \\ p_{2} & \text { pressure of burned gases immediately behind detonation wave } \\ p_{3} & \text { pressure of burned gases after detonation wave passage } \\ t & \text { time } \\ t_{D D T} & \text { deflagration-to-detonation transition time } \\ u & \text { velocity } \\ u_{C J} & \text { Chapman-Jouget detonation velocity } \\ u_{e} & \text { exhaust velocity } \\ x & \text { distance } \\ \tau & \text { characteristic time } \\ \tau_{\mathrm{I}} & \text { characteristic time for detonation wave propagation } \\ \tau_{\mathrm{II}} & \text { characteristic time for rarefaction wave propagation } \\ \tau_{\mathrm{III}} & \text { characteristic time for tube blowdown }\end{array}$




\section{TECHNICAL PUBLICATION}

\section{DEVELOPMENT OF A GAS-FED PULSE DETONATION RESEARCH ENGINE}

\section{INTRODUCTION}

Pulsed detonation architectures have the potential to revolutionize aerospace propulsion and power systems. This assertion is derived from the unique performance gains associated with unsteady reacting flow effects and from the cost reductions associated with a highly simplified design configuration. Consequently, there is considerable interest in obtaining an accurate assessment of representative performance and cost benefits.

It should be noted that there are two fundamental architectural classifications for pulse detonation engines (PDEs). That is, they can either obtain air from the surrounding atmosphere or acquire an oxidizer from onboard storage tanks. In the former case, PDEs represent an attractive low-cost alternative to turbojets based on their potential for surpassing intrinsic limits on scalability, operating range, efficiency, and manufacturing costs. In the latter case, the device is referred to as a pulse detonation rocket engine (PDRE).

Generally speaking, PDEs operate on an intermittent cycle by filling a chamber with reactants and inducing ignition in an energetic fashion such that a combustion detonation wave is rapidly established. The high propagation speed of the detonation wave implies orders-of-magnitude increase in combustion rates relative to the deflagration mode, and the chemical energy is completely released within a very narrow region behind the leading shock wave. As a result, the combustion process takes place at nearly constant volume, which yields a higher postcombustion temperature (i.e., higher performance or specific impulse $\left(I_{s p}\right)$ ) than a constant pressure process). The detonation wave has the added benefit of attaining a higher peak pressure.

In fact, contemporary interest in PDREs arises primarily from advantages that accrue from the significant combustion pressure rise developed by the detonation process. Because PDREs do not require extreme precompression of the working fluid to fill the chamber, it should be possible to eliminate the need for large and heavy turbopumps. This potential advantage must be carefully assessed, of course, in view of the added requirement for fast-acting robust valves. Furthermore, the wide throttling range of a PDRE should not be ignored as a favorable attribute since it can play an important role in many mission scenarios.

Although PDREs are expected to achieve greater $I_{s p}$ (due to the higher peak temperature) and greater design simplicity (due to the relaxed turbopump requirement), it is not yet clear whether they will prove superior to conventional rocket engines from a systems point of view. Basic scientific feasibility has been clearly established in several experimental and theoretical studies, as noted in recently published review articles, ${ }^{1-3}$ but the unsteady operational attributes of PDEs complicate their analysis when including nonideal effects, and it is difficult to make the needed system level assessments. 
Surely, significant strides are being made with respect to the development of design strategies and performance optimization, ${ }^{49}$ but it should be recognized that they are still at an early stage of development. Furthermore, there are critical operational issues that must be addressed before the PDE concept will ever be realized in practice, and reliable empirical data is badly needed.

A number of private companies are engaged in the design and development of various prototype engines to address technical uncertainties and reduce risk, but the acquired data are not widely disseminated due to proprietary concerns. Therefore, a critical need exists for highly instrumented laboratory research engines that will permit the establishment of an empirical database, which can be widely disseminated throughout industry, government, and academia. The Naval Postgraduate School and the Air Force Research Laboratory at Wright-Patterson Air Force Base (AFB), for instance, have each built research engines and initiated fundamental research programs in order to have an independent source of empirical data. ${ }^{10,11}$ This Technical Publication describes the development of a low-cost gas-fed pulse detonation research engine, which is intended to serve in a similar capacity at the NASA Marshall Space Flight Center (MSFC). 


\section{PROJECT OBJECTIVES}

The MSFC pulse detonation research engine, designated as PDRE-G-1 (gas-fed series, model No. 1), was developed to satisfy a number of diverse needs. The principal objective overriding all other factors was the desire to obtain a simple and flexible research device with which to generate empirical data independent of proprietary concerns. It should be emphasized that the resulting device is a research engine and is not intended as an evolutionary step toward a production engine.

The hope is that the PDRE-G-1 device will serve as a flexible research tool for investigating fundamental physical processes and basic operational issues. The resulting knowledge can then be widely disseminated so that it may have the broadest possible impact on design tool development, design optimization, and system analysis efforts. The device could also be used as a test-bed for developing critical enabling technologies that may one day find use on a practical production engine.

Specifically, the MSFC PDRE-G-1 engine was designed to accomplish the following technical objectives:

- Provide a nonproprietary empirical database with respect to PDE performance and operational characteristics;

- Support development of theoretical/computational fluid dynamics (CFD) analysis tools as well as engineering design tools;

- Develop/validate PDE design scaling laws;

- Address system integration issues;

- Improve understanding of detonation physics;

- Explore innovative design strategies and configurations related to valves, propellant injection, nozzles, detonation initiation, electrical power extraction, etc.;

- Improve definition of system operational requirements related to propellant pumping, electrical power requirements, control, etc.;

- Serve as a test-bed for subsystem component testing; and,

- Lay the groundwork for development of a liquid-fed pulse detonation research engine. 


\section{DESIGN STRATEGY}

The guiding design strategy for the PDRE-G-1 engine was to achieve a simple and flexible research apparatus that would be inexpensive to build and operate. Therefore, the engine was designed as a heat sink device and, as such, can only be operated in a burst mode with run durations of a few seconds. From a research perspective, this is not a critical limitation since short duration tests are entirely adequate for acquiring the data of primary interest.

In keeping with the low-cost design strategy, maximum use was made of standard off-the-shelf industrial or automotive components wherever possible. For example, the injector head assembly and primary tube were fabricated from standard pipe and flanges, and simple coaxial injectors were incorporated into the design. Standard industrial solenoid valves were incorporated to control the propellant flow to the injectors.

In a similar simplistic fashion, a high-performance automotive electronic ignition system was adapted for use, and spark plugs were mounted at various locations to permit exploration of alternative configurations for detonation initiation. Because PDEs require precise control over valve cycling and ignition timing, significant effort was expended to develop a microprocessor-based engine control system that incorporated fiber optic coupling of the processor digital control signals to the engine.

As a research device, it was deemed necessary to make adequate provisions for the engine to be highly instrumented. Therefore, sensor and optical diagnostic access ports were incorporated throughout the engine design. Additional preparations related to operational support included assembly of propellant storage and supply lines, construction of a rigid test stand, and development of test procedures and special precautionary measures due to the unique hazards associated with PDE operation.

\subsection{Integrated Injector Head Assembly}

The core of the engine is the integrated injector head assembly, which is fabricated entirely from stainless steel components and materials. This assembly, shown schematically in figure 1, consists of the initiator tube containing the primary coaxial injector, which is inserted directly through the center of the injector head. The injector head face has four auxiliary coaxial injectors distributed at $90^{\circ}$ intervals around the initiator tube. The primary engine tube attaches to a flange, which is in turn mounted to the injector head assembly.

The primary coaxial injector is attached to the rear of the initiator tube such that the propellants thoroughly mix in the initiator and then exit into the primary tube. The initiator tube is $15-\mathrm{cm}$ long and currently has a 1.1-cm-diameter bore. The initiator tube wall was designed sufficiently thick to accommo-

date a larger diameter bore if necessary. A spark plug can also be inserted into the initiator tube at a point $2.5 \mathrm{~cm}$ downstream from the primary injector. 
The auxiliary injectors were incorporated into the design to provide additional flexibility and to permit exploration of alternative propellant injection schemes. For example, they could be used to inject the primary propellant or buffer gases as desired. These injectors have a very simple design in which the center posts are silver soldered to the initiator body and inserted through holes in the injector-head face to form a coaxial configuration. The center posts are fed through holes bored into the initiator body and the annuli are fed through holes bored into the injector head. It should be noted that the primary injector is fabricated in a similarly simplistic fashion.

Photographs of the integrated injector head assembly are shown in figures 2 and 3 while undergoing preparations for preliminary shakedown testing of the initiator tube. The individual feedlines to the injectors as well as the individual auxiliary coaxial injectors can be clearly seen.

\subsection{Primary Engine Tube}

The basis for the primary engine tube was a $90-\mathrm{cm}$-long section of 5-cm-diameter schedule-40 stainless steel pipe. This simple approach was expedient and inexpensive, and it provided sufficient design margin for operation in a heat sink mode despite the severe thermal and structural load cycles. The pipe was threaded at one end and could be directly mated with the integrated injector-head tube flange.

The only required machining was the drilling of holes to accept various bosses for spark plugs, sensor ports, and optical diagnostic windows. Sensor ports were located at 10 -cm intervals along the primary tube axis and two opposing spark plug bosses were located near the end of the tube closest to the injector head assembly. Diametrically opposed optical window ports were located at the same axial location as the sensor ports and the spark plug bosses. Subsequent shakedown testing of the device demonstrated the thermal and structural integrity of the primary tube design.

\subsection{Ignition and Valve Control Circuits}

Successful operation of any PDE demands precise control over valve and ignition timing. Therefore, considerable attention was devoted to the development of adequate control circuits. It was decided at an early stage that a digital microprocessor would be used for basic engine control since this would provide the highest degree of flexibility and would be readily adaptable for the exploration of advanced automatic control techniques.

It was also decided to pursue a strategy whereby the digital control signals would be fiber optically coupled to the engine. Fiber optic coupling has many attractive benefits including complete electrical isolation of the microprocessor control system from the engine, high signal-to-noise ratio, low signal attenuation over long transfer distances, high reliability, and greater simplicity in the engine wiring harness. Following this strategy, the first objective was to develop a simple low-cost optical transmitter and receiver pair, which could be utilized in both the ignition and valve control circuits. 
In the resulting design, the transistor-transistor logic (TTL) optical transmitter takes the control signal from the microprocessor and converts it into a light pulse using a simple transistor circuit and a fast response ( $>10 \mathrm{MHz}$ ) infrared light emitting diode (Motorola Model MFOE71). The light pulse from the transmitter is then coupled to a $1,000-\mu \mathrm{m}$ plastic fiber optic cable. At the receiving end, a simple $5-\mathrm{kHz}$ TTL optical receiver, based on a standard phototransistor (Motorola Model MFOD72), detects the light pulse emerging from the fiber optic and converts it into a crisp low-level TTL signal using a Schmidt trigger. The final design diagrams for the ignition and propellant valve control circuits are shown in figures 4 and 5 , respectively.

In the ignition circuit, the TTL signal from the optical receiver is fed into a transistor switch, which shorts the trigger terminal of a capacitive discharge ignition (CDI) controller (Model MSD 6A). This action generates multiple 400-V discharges across the primary of a 100:1 transformer coil, and the resulting 40-kV output in the secondary coil is transmitted to a spark plug. Multiple 110-mJ gas discharges are then formed at the spark plug electrodes yielding an effective and energetic ignition source.

In the solenoid valve circuit, the TTL signal from the optical receiver is connected to a solid-state relay, which directly controls propellant valve activation. The fuel and oxidizer valves are controlled with independent circuits, and additional independent circuits are available for controlling auxiliary valves as needed.

Prior to installation on the engine, these circuits were built and tested on the bench to confirm anticipated performance. The test results demonstrated excellent response and signal-to-noise characteristics.

\subsection{Microprocessor-Based Control System}

Engine operation was completely automated using a computer-based control system. This approach gives precise control over engine timing variables and provides a suitable framework for implementing advanced feedback control techniques as desired.

The basis of the control system is a National Instruments modular PXI platform with embedded PC controller. Currently, the TTL engine control signals are generated by an 8-channel 32-bit counter/timer module with software control under a customized program written in the LabVIEW graphical programming language. This program permits precise adjustment of the duty cycle and phasing of each control signal. For example, figure 6 shows the control signals acquired at the output of the TTL optical transmitters during a $40-\mathrm{Hz}$ initiator shakedown test. These waveforms demonstrate a capability for producing high-quality signals with very precise timing. 


\section{SHAKEDOWN TESTING}

To date, a number of shakedown tests have been conducted on the initiator and the full PDRE-G-1 engine assembly. All of these firings have been conducted with hydrogen/oxygen propellant mixtures. The principle objective of these firings was to validate system and subsystem functionality and to verify the attainment of true detonation conditions. The basic approach was to acquire waveforms from dynamic pressure transducers at selected locations. The combustion wave velocity could then be deduced from its measured time of flight and compared against theoretical Chapman-Jouget (C-J) values.

For further reference, the theoretical C-J detonation characteristics are provided in figure 7 . This plot shows the detonation velocity and pressure ratio across the shock as a function of the hydrogen volume fraction. For a stoichiometric mixture ratio, the detonation velocity is roughly $2.8 \mathrm{~km} / \mathrm{sec}$ and the pressure ratio is about 18.7, which is near the peak value for $\mathrm{H}_{2} / \mathrm{O}_{2}$ mixtures.

\subsection{Initiator Test Firings}

In general, the flame front can evolve along three possible trajectories as indicated in the positiontime wave diagram of figure 8 . If the ignition energy $\left(E_{i g n}\right)$ exceeds the critical energy for direct detonation initiation $\left(E_{c}\right)$, then the detonation wave is immediately formed at the ignition point and propagates down the tube at the C-J detonation velocity. If $E_{i g n}<E_{c}$ and a mechanism such as turbulent mixing is available to accelerate the flame, then the flame can gradually accelerate beyond the laminar flame speed and eventually undergo deflagration-to-detonation transition (DDT). If $E_{i g n}<E_{c}$ and no mechanism exists for accelerating the flame, then the flame will propagate down the tube at the laminar flame speed. Because the energy deposition of the PDRE-G-1 ignition source $(110 \mathrm{~mJ})$ was much less than the critical initiation energy for oxygen/hydrogen mixtures, it was necessary to rely on a DDT initiation strategy. Furthermore, the time and length scales for DDT would have to be very short for practical utilization.

To facilitate evaluation of the initiator tube, an identical copy was machined from mild steel and outfitted with three sensor ports as shown in figure 9 . Each port was located $2.5 \mathrm{~cm}$ from its neighbor with the last port located $1.9 \mathrm{~cm}$ from the initiator tube exit. Pressure waveforms were then acquired at a $20-\mathrm{Hz}$ firing rate while tuning the propellant injection rate to obtain the highest possible combustion wave speed.

The measured results for the smooth bore initiator tube are shown in figure 10 with an indicated combustion wave speed of $540 \mathrm{~m} / \mathrm{sec}$. This value was significantly lower than the theoretical C-J value implying that DDT was not being attained. Clearly, the smooth bore tube was not providing sufficient flame acceleration.

At this point, it was decided to take advantage of the phenomena discovered by K.I. Schelkin during a series of careful investigations carried out between 1945 and 1949 in which he observed that 
flame propagation speed would dramatically increase in tubes with rough walls. ${ }^{12}$ His observation gave birth to the now well-known Schelkin spiral for inducing rapid transition to detonation conditions. Later work by L.P. Kayushin demonstrated similar effects using grids and orifices in the tube. ${ }^{13}$ The now widely accepted view is that obstacles in the flow generate intense turbulence mixing which induces rapid acceleration of the flame. The Schelkin spiral and its effect on turbulent mixing and flame acceleration are illustrated in figure 11.

Following this line of reasoning, another series of initiator tests were conducted using two different Schelkin spirals. Spiral No. 1 was constructed from $1 / 25$-in.-diameter wire with a 1/4-in. pitch, and spiral No. 2 used constructed from $1 / 40$-in. diameter wire with a $1 / 4$-in. pitch. The measured pressure waveforms for these tests are shown in figures 12 and 13, and the combustion wave speed was observed to increase as anticipated. The measured value for spiral No. 2 was $1.4 \mathrm{~km} / \mathrm{sec}$, which was still far lower the theoretical C-J value; however, the measured value for spiral No. 2 was $2.4 \mathrm{~km} / \mathrm{sec}$, which is in close agreement with the theoretical value for an $\mathrm{H}_{2}$ volume fraction near 0.5 .

\subsection{PDRE-G-1 Test Firings}

Preliminary testing of the fully assembled PDRE-G-1 research engine was initiated upon completion of the initiator shakedown tests. The engine was installed on the test stand, as shown schematically in figure 14, and outfitted with dynamic pressure transducers at the indicated port locations. Also note that the engine was equipped with a thrust transmission structure and a dynamic load cell for the purpose of making time-resolved thrust measurements. Optical window ports were also available for flow visualization.

In these tests, two additional spark plugs were mounted in the primary tube. This was done to provide multiple ignition sources as a means of reducing the chance for misfire. It should also be noted that the small fast-acting solenoid valves used during the initiator test firings were replaced with larger but much slower industrial solenoid valves in order to minimize pressure losses. The slower valve response limited the engine operating frequency to about $5 \mathrm{~Hz}$. The entire propellant flow was injected through the primary injector during all tests. The auxiliary injectors were not utilized. Following our established test strategy, pressure waveforms were first acquired with a smooth bore primary tube while tuning the propellant flow to obtain high combustion wave speed.

\subsubsection{Detonation Characteristics}

The measured pressure waveforms near the end of the primary tube (ports 7 and 8 ) are shown in figure 15 for the smooth bore case. With an indicated flame speed of only $505 \mathrm{~m} / \mathrm{sec}$, it was clear that detonation conditions were not being attained. Since the initiator tube with Schelkin spiral was known to detonate, there was some hope of achieving detonation wave diffraction into the primary tube. However, the critical tube diameter for hydrogen/oxygen is on the order of $2 \mathrm{~cm}$, and the current initiator tube diameter is only $1.1 \mathrm{~cm}$. It is clear from our results that the ratio of initiator tube diameter to primary tube diameter must be increased in order to obtain successful detonation propagation into the primary tube. 
This question is of great interest for future investigation, but the most expedient approach was to investigate the utilization of a Schelkin spiral for inducement of deflagration-to-detonation transition. Along these lines, a section of $1 / 8$-in. stainless steel tube was shaped into a spiral having a 5 -cm outside diameter, a $3 / 4-i n$. pitch, and a length equal to the primary tube length. This spiral was placed inside the primary tube and the engine tests were repeated.

The resulting pressure waveforms near the end of the primary tube (ports 7 and 8) are shown in figure 16. In this case, combustion wave speed was observed to increase to $2.2 \mathrm{~km} / \mathrm{sec}$. This value is indicative of detonation conditions and corresponds to an $\mathrm{H}_{2}$ volume fraction near 0.5 as may be deduced from inspection of figure 7 . This implied that the engine was operating with a lean mixture ratio.

Unfortunately, the ability to set an accurate mixing ratio is difficult at this juncture because the current setup has no provision for accurately measuring flow rates. It is only possible to make estimates based on an approximate value for the valve flow coefficient and the known supply pressures. Therefore, future work has been planned to address the development of an accurate flow rate measurement capability.

It was uncertain where the transition from deflagration to detonation actually occurred so another series of tests was conducted to obtain the axial distribution in flame speed along the primary tube. The resulting pressure waveforms for ports $2-8$ are shown in figure 17 , and it was observed that the detonation velocity remained virtually constant at $2.2 \mathrm{~km} / \mathrm{sec}$ along the interrogated length. This implied that detonation transition occurred before port 2, and that the Schelkin coil could be shortened to a length $<20 \mathrm{~cm}$ and still achieve a similar result. This hypothesis has yet to be attempted in practice, but will be addressed further as development work continues.

\subsubsection{Thrust Characteristics}

The engine thrust characteristics were of immense interest, and the availability of a fast response dynamic load cell permitted the acquisition of time-resolved profiles for installed engine thrust. The total engine impulse could subsequently be deduced through integration of these measured thrust profiles. The term "installed thrust" is used because the engine and thrust transmission structure behave as an effective spring-damper system. As such, the resulting thrust profile, measured by the dynamic load cell, depends upon the dynamic response of the installed engine structure, which is in turn governed by the structural mass, effective spring constant, and effective damping characteristics. Therefore, the installed engine thrust profile does not necessarily correspond with the fluid dynamic force profile acting on the engine.

The ideal fluid dynamic forcing function may be deduced from a consideration of the ideal PDRE cycle process as illustrated in figure 18. For the simple straight tube engine geometry, the only fluid dynamic force acting on the engine is the surface pressure at the head of the engine. Once the detonation has been initiated and the flame front begins to propagate through the tube, a centered expansion occurs between the detonation wave and the engine head with the generation of right-running rarefaction waves. The detonation wave exits the tube at time $\tau_{\mathrm{I}}=L_{c} / u_{C J}$, and left-running rarefaction waves then run back down the tube at the speed of sound of the burned gases $\left(c_{3}\right)$. The time for the left-running rarefaction wave to reach the engine head is $\tau_{\mathrm{II}}=L_{c} / c_{3}$. At this point, the tube experiences an exponential blowdown of the remaining combustion gases over a characteristic time $\tau_{\text {III. These detonation and rarefaction wave propa- }}$ gation trajectories are illustrated in the position-time wave diagram of figure 19. 
Based on the idealized blowdown process above, the engine head pressure profile can be approximated as a constant value from the time of detonation initiation to the time for the left running rarefaction to return to the point of ignition $\left(\tau_{\mathrm{I}}+\tau_{\mathrm{II}}\right)$. The remaining portion of the thrust can then be approximated by an exponential decay with a characteristic time of $\tau_{\mathrm{III}}$. This idealized engine head pressure profile is illustrated in figure 20.

It should also be noted that the thrust profile depends on the tube fill conditions. If the tube is completely filled with propellant, the detonation wave will propagate through the entire tube and fill it with combustion gases. These gases are expelled during the subsequent blowdown process. If the tube is only partially filled, however, some quantity of air must be pushed out ahead of the combustion gases.

Clearly, maximum thrust will be obtained for the filled tube condition, but experiments carried out by Professor V.V. Mitrofanov have demonstrated that maximum $I_{s p}$ can occur when the tube is underfilled. ${ }^{14}$ That is, transference of combustion energy to the free additional air mass in the tube can be more effective from a propellant consumption standpoint.

Following this line of thought, an attempt was made to operate the PDRE-G-1 engine for filled and underfilled tube conditions. The filled tube condition had been demonstrated in the previous set of firings. It was only necessary to fix the propellant supply pressure and increase the operating frequency to obtain an underfilled tube condition.

The effect of the tube filling condition on the exhaust plume is demonstrated in figures 21 and 22 , which show long exposure photographs obtained during night firings for filled and underfilled tube conditions, respectively. The difference between the two cases is clearly observed from the plume luminosity. For the filled case, the ejected combustion gases create a highly luminous expanding plume, which wraps back around the nozzle. For the underfilled case, the luminous plume is confined to a dim narrow cone.

An attempt was then made to acquire time-resolved installed thrust measurements for these two cases. The resulting ensemble-averaged thrust waveforms are shown in figure 23 . Both profiles show a rapidly rising thrust pulse, which peaks at a time that is strongly correlated with the exit of the detonation wave from the tube, and then exhibits a slow decay as the tube blows down. These results do not correspond to the idealized thrust profile of figure 20 due to the spring-damper response characteristics, but the results are consistent with previous time-resolved installed thrust measurements obtained by the author using single-shot detonation tubes. ${ }^{15}$

As previously noted, the timescale for passage of the detonation wave through the tube $\left(\tau_{\mathrm{I}}\right)$ appears to be correlated with the rise time of the thrust pulse. This quantity is readily determined from the ratio of the chamber length, $L_{c}$, to the detonation velocity, $u_{D}$, such that $\tau_{1}=L_{c} / u_{D} \approx 400 \mu \mathrm{sec}$. Due to the Taylor wave, a centered expansion occurs between the detonation wave and closed end of the tube, where the velocity must go to zero. The resulting pressure on the head of the engine determines the fluid dynamic forcing function for the spring-damper system, but the shape of the installed thrust profile depends on dynamic response of the system. 
The peak thrust value for the underfilled tube case $(\approx 150 \mathrm{lbf})$ is about half that obtained for the filled tube case $(\approx 270 \mathrm{lbf})$. By integrating these installed thrust profiles, it was also possible to obtain the total impulse associated with each condition. The results were $0.21 \mathrm{lbf} \bullet \mathrm{sec}$ and $0.41 \mathrm{lbf} \bullet \mathrm{sec}$, respectively.

Because of the uncertainty in the propellant flow rates at this stage of development, there is considerable uncertainty as to the exact quantitative value of the mixture ratio and the fill amount. Therefore, no attempt was made to deduce the specific impulse from this data. Deduction of $I_{s p}$ will be deferred until an accurate flow rate measurement becomes available. 


\section{CONCLUSIONS}

A low-cost gas-fed PDRE has been successfully developed and placed into operation to serve as an independent source of empirical data and as a test-bed for developing the required enabling technologies for this class of engine. Preliminary shakedown tests using hydrogen/oxygen propellants confirmed the attainment of detonation conditions with measured combustion wave speeds in the range of $2.2-2.4 \mathrm{~km} / \mathrm{sec}$ when using a Schelkin spiral. Time-resolved thrust measurements were also acquired for filled and underfilled tube conditions. Peak thrust values were $270 \mathrm{lbf}$ and $150 \mathrm{lbf}$, respectively. Further development efforts are planned to improve engine performance and operating capabilities and to acquire improved capabilities for more accurate measurement of engine operating parameters. 


\section{REFERENCES}

1. Bussing, T.; and Pappas, G.: "Pulse Detonation Engine Theory and Concepts," Developments in High-Speed-Vehicle Propulsion Systems, Murthy, S.N.B.; and Curran, E.T. (eds.), Vol. 165, Progress in Astronautics and Aeronautics, AIAA, NY, pp. 421-472, 1997.

2. Lynch, E.D.; and Edelman, R.B.: "Analysis of the Pulse Detonation Wave Engine," Developments in High-Speed-Vehicle Propulsion Systems, Murthy, S.N.B.; and Curran, E.T. (eds.), Vol. 165, Progress in Astronautics and Aeronautics, AIAA, NY, pp. 473-516, 1997.

3. Kailasanath, K.: "Applications of Detonation to Propulsion-A Review," AIAA 99-1067, 1999.

4. Cambier, J.L.; and Tegner, J.K.: "Strategies for Pulsed Detonation Engine Performance Optimization," J. Propulsion and Power, Vol. 14, No. 4, pp. 192-196, 1998.

5. Cambier, J.L.: "Preliminary Modeling of Pulse Detonation Rocket Engines," AIAA 99-2659, 1999.

6. Li, C.; Kailasanath, K.; and Patnaik,G.: "A Numerical Study of Flow Field Evolution in a Pulsed Detonation Engine," AIAA 2000-0314, 2000.

7. Eidelman, S.; Sharov, D.; and Book, D.: "Aerothermodynamic Analysis of Pulse Detonation Engines," AIAA 2000-3892, 2000.

8. Ebrahimi, H.B.; Mohanraj, R.; and Merkle, C.L.: "Multi-Level Analysis of Pulse Detonation Engines," AIAA 2000-3859, 2000.

9. Mohanraj, R.; Merkle, C.L.; and Ebrahimi, H.B.: "Modeling of Pulse Detonation Engine Operation," AIAA 2001-0475, 2001.

10. Brophy, C.M.; Netzer, D.W.; Sinibaldi, J.O.; and Johnson, R.G.: "Operation of a JP10/Air Pulse Detonation Engine," AIAA 2000-3591, 2000.

11. Schauer, F.; Stutrud, J.; and Bradley, R.: "Detonation Initiation Studies and Performance Results for Pulsed Detonation Engine Applications," AIAA 2001-1129, 2001.

12. Schelkin, K.I.: Zhurnal Eksperimental' noi I Teoreticheskoi Fiziki, 25 (5) 1953.

13. Kayushin, L.P.: "The Influence of External Friction and Heat Exchange on the Motion of an Ignition Surface and a Shock-Discontinuity in a Chemically Reactive Medium," in Gas Dynamics and Physics of Combustion, NASA-TT-F-79, pp. 53-65, 1962.

14. Mitrofanov, V.V.: Lavrentyev Institute for Hydrodynamics, Novosibirsk, Russia, Private Communication, March 2001.

15. Litchford, R.J.: "Integrated Pulse Detonation Propulsion and Magnetohydrodynamic Power," NASA/ TP_2001-210801, January 2001. 


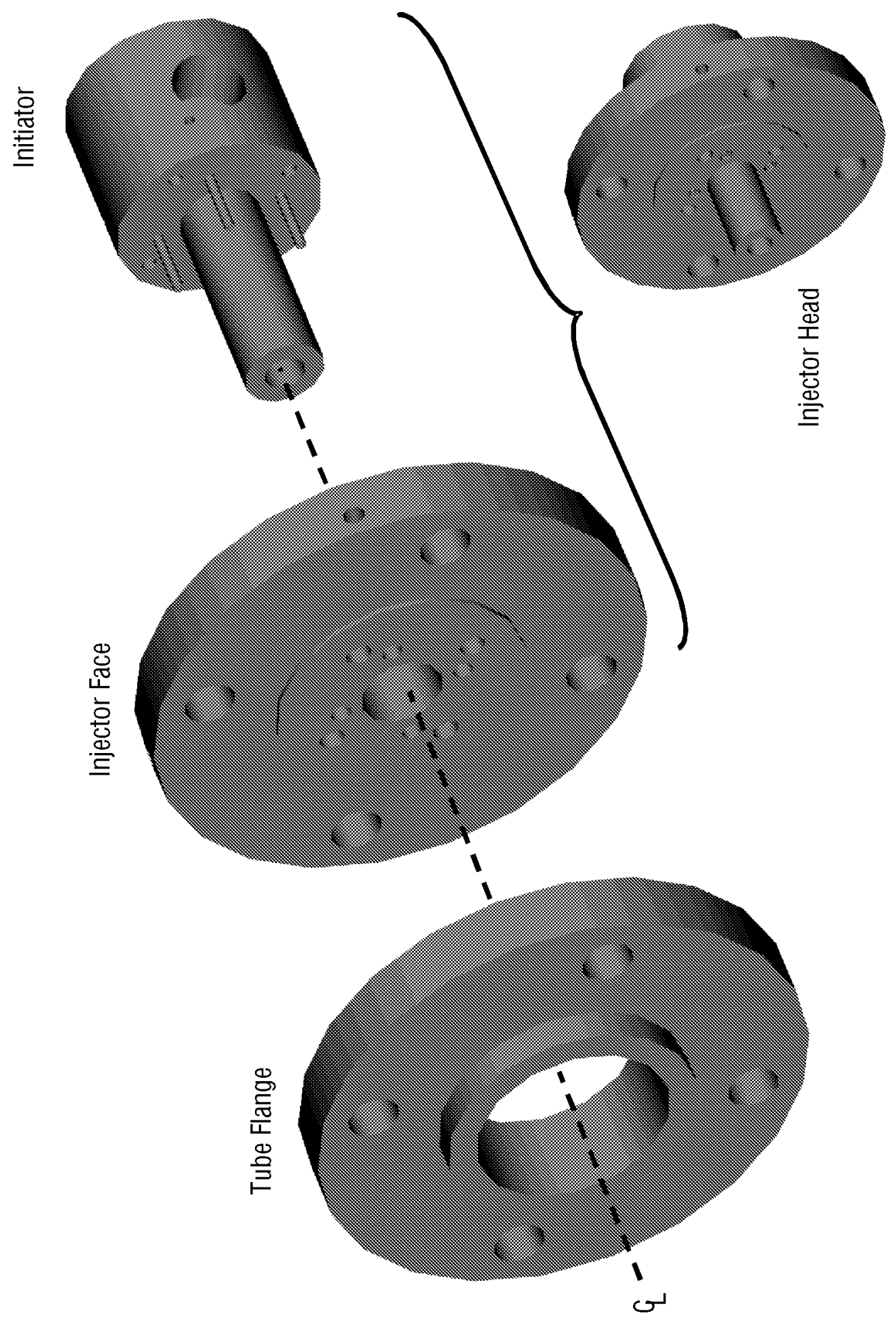

Figure 1. Schematic of integrated injector head assembly. The initiator tube containing the primary coaxial injector is inserted through the center of the injector head face. Four auxiliary coaxial injectors are distributed at $90^{\circ}$ intervals around the central initiator tube. 


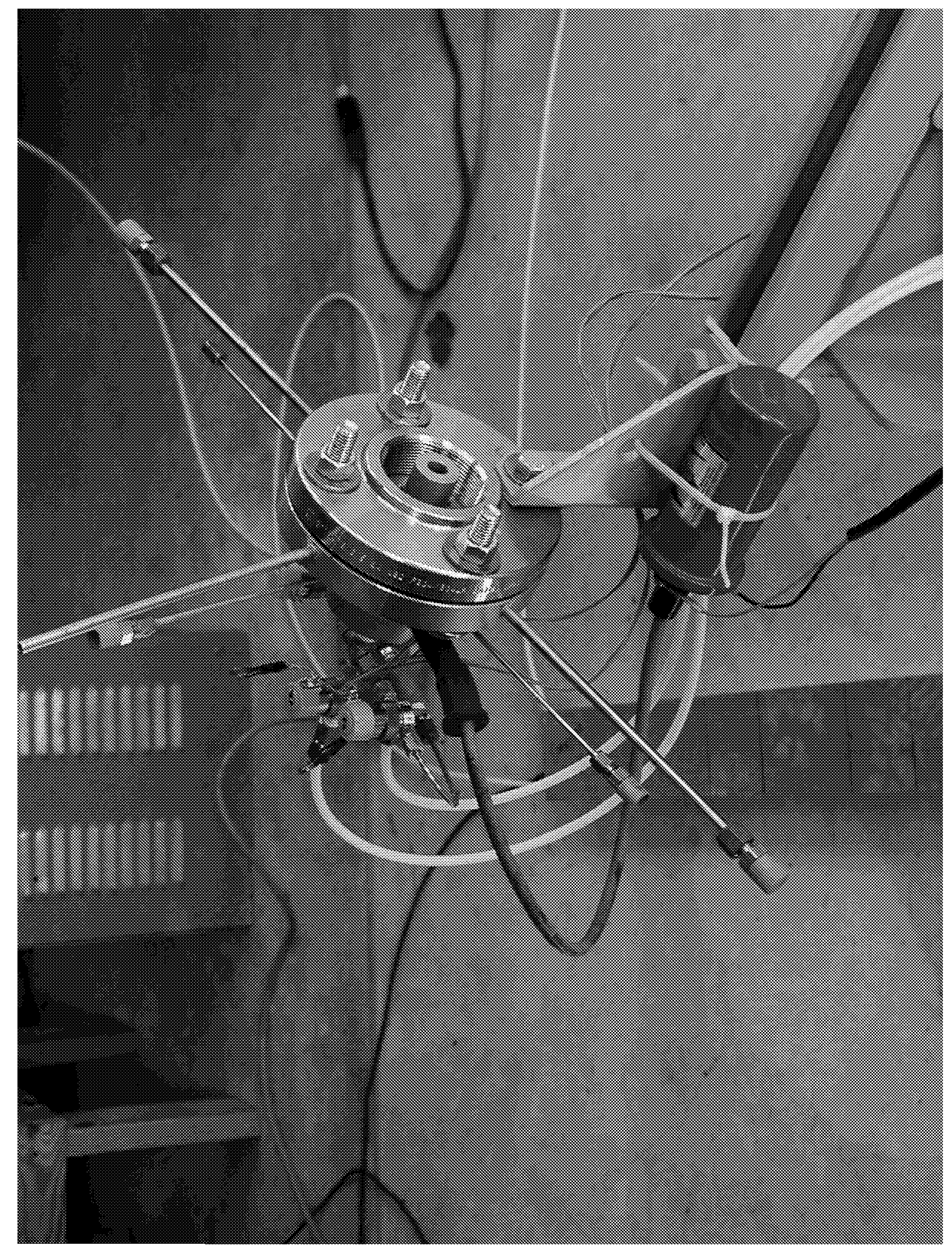

Figure 2. Photograph of integrated injector head assembly in preparation for preliminary shakedown testing (side view). 


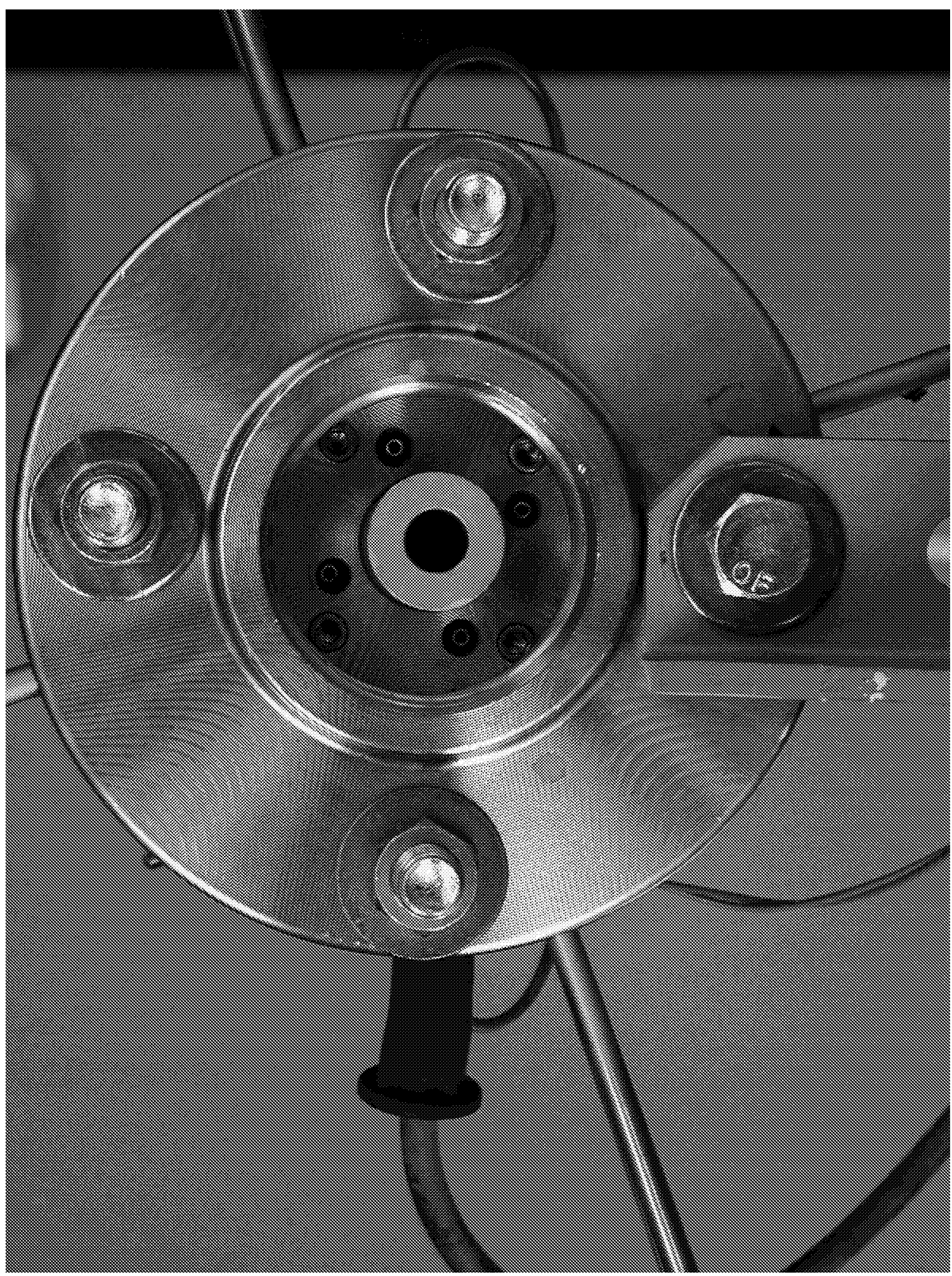

Figure 3. Photograph of integrated injector head assembly in preparation for preliminary shakedown testing (injector face view). 


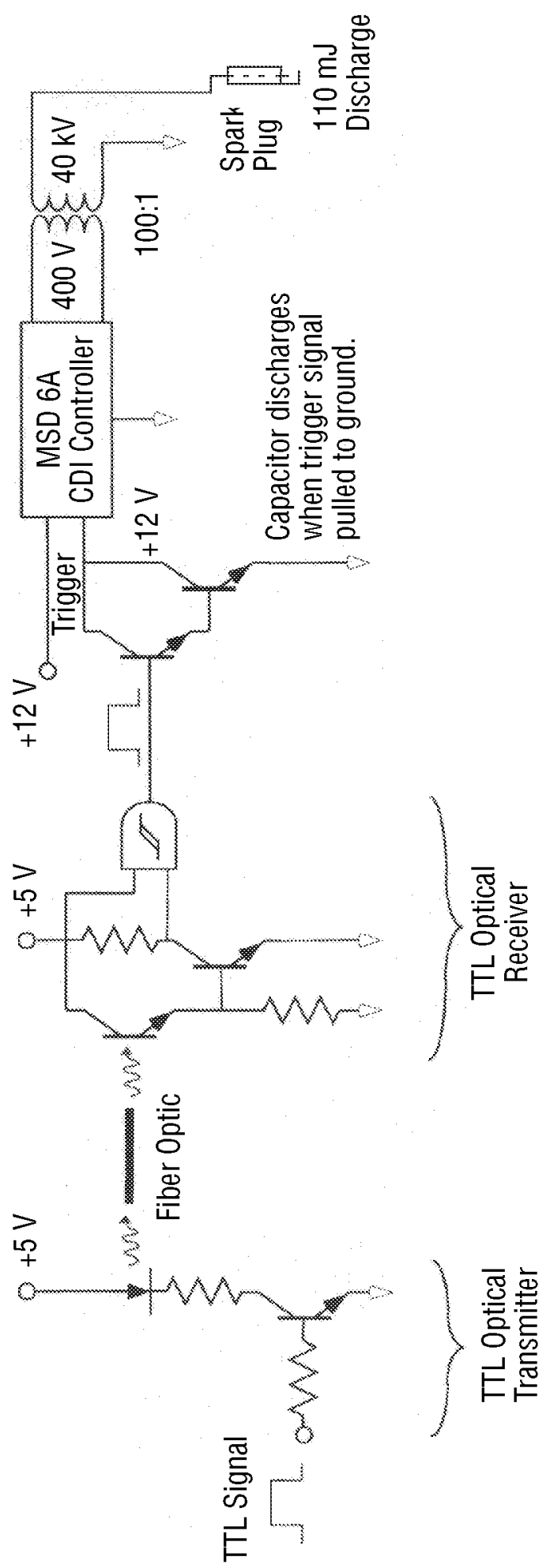

Figure 4. Schematic of the igniter control circuit using fiber optic coupling from a TTL optical transmitter to a TTL optical receiver. 

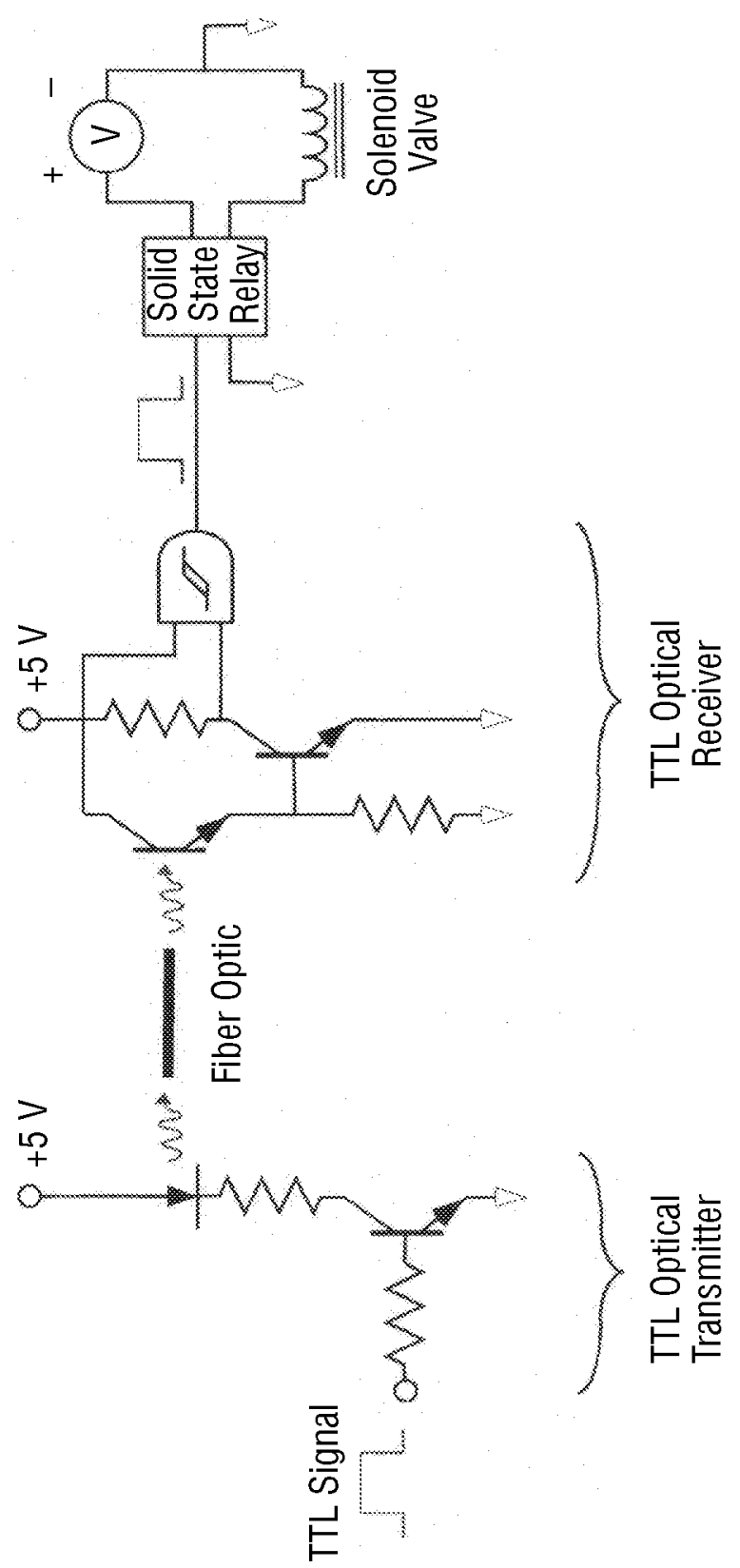

Figure 5. Schematic of the propellant valve control circuit using fiber optic coupling from a TTL optical transmitter to a TTL optical receiver. 


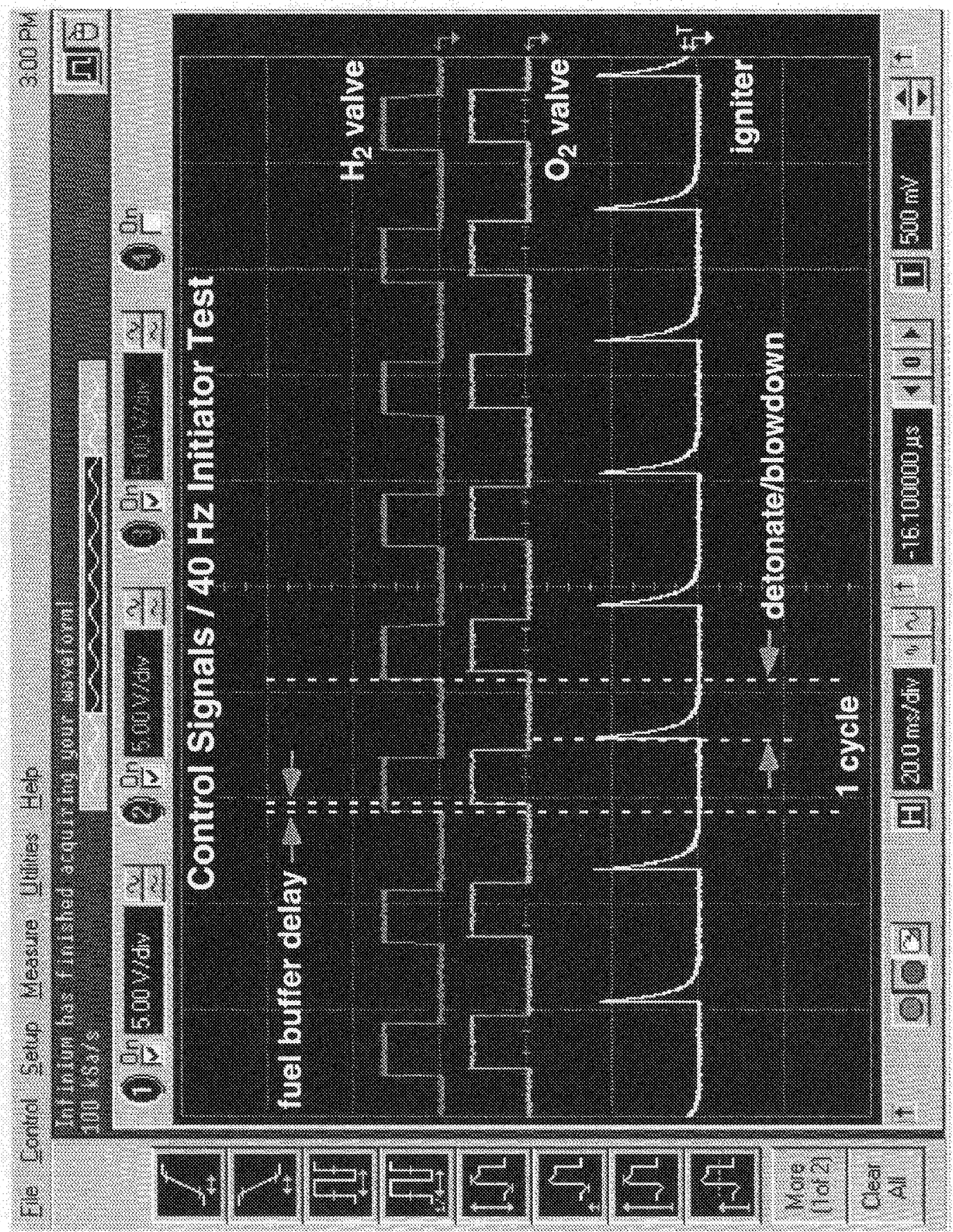

Figure 6. Microprocessor control signals acquired at the output of the TTL optical receivers during a $40-\mathrm{Hz}$ initiator shakedown test. 


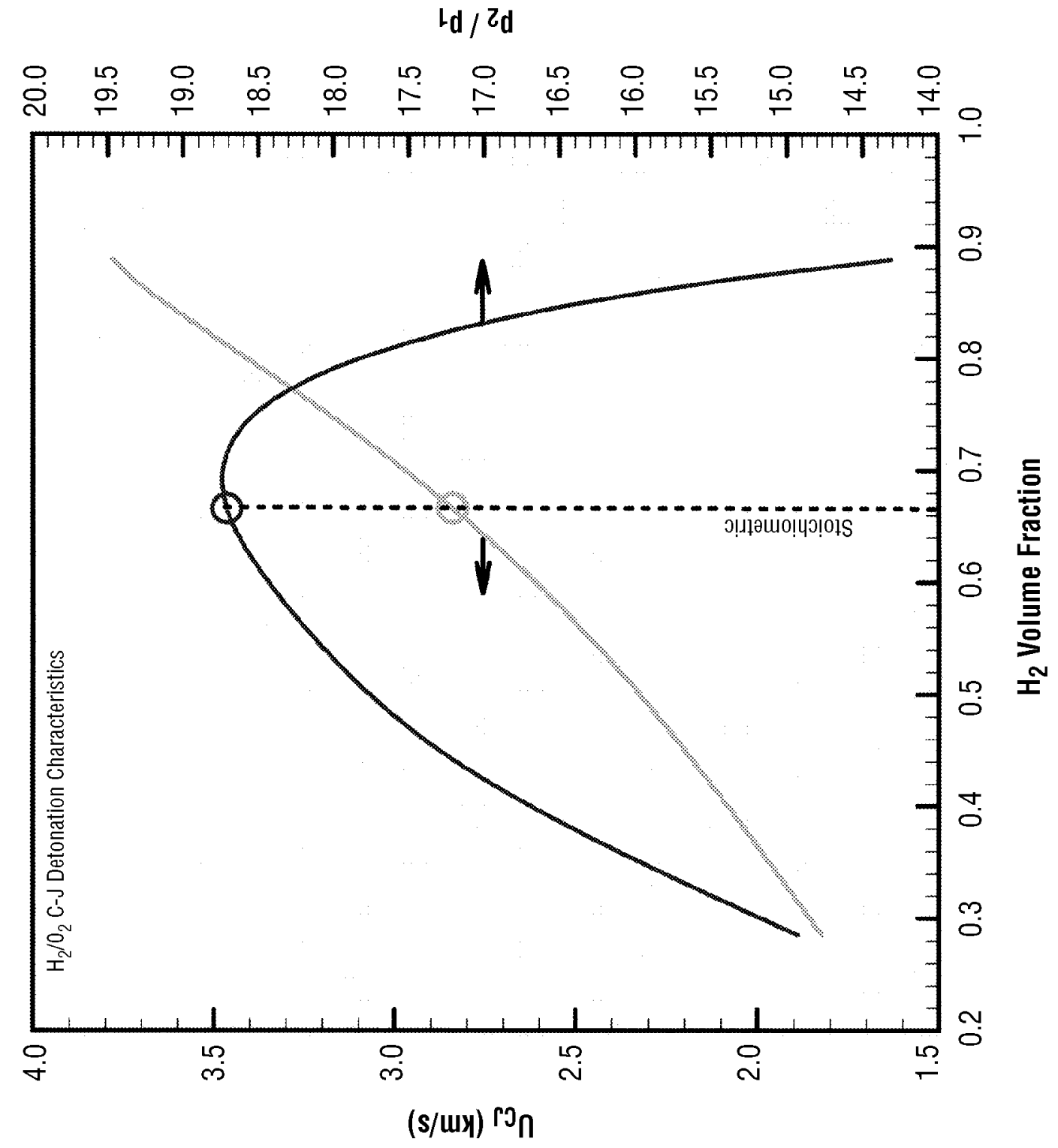

Figure 7. Theoretical C-J detonation characteristics as a function of $\mathrm{H}_{2}$ volume fraction. 


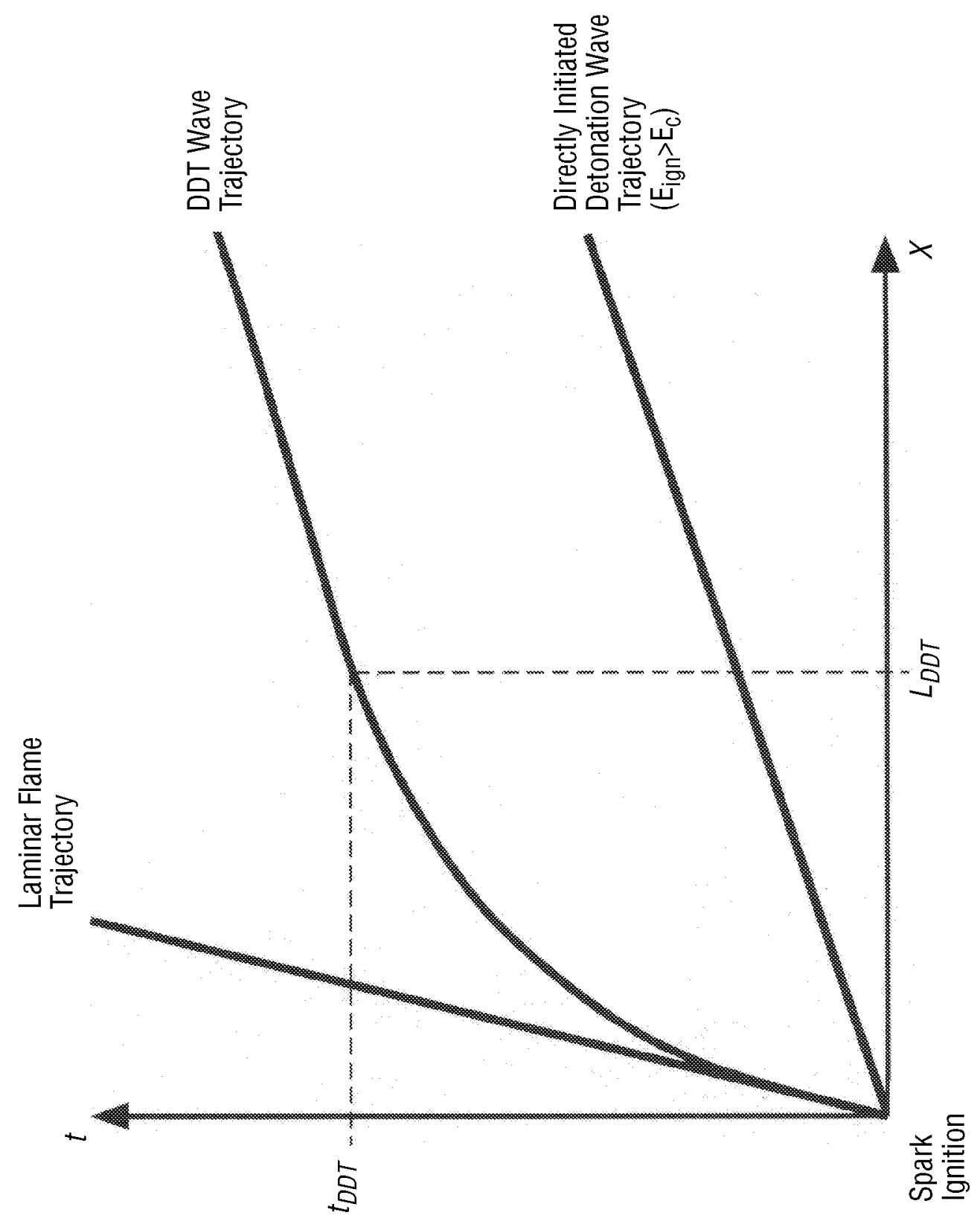

Figure 8. Theoretical flame front trajectories on the position-time wave diagram. 


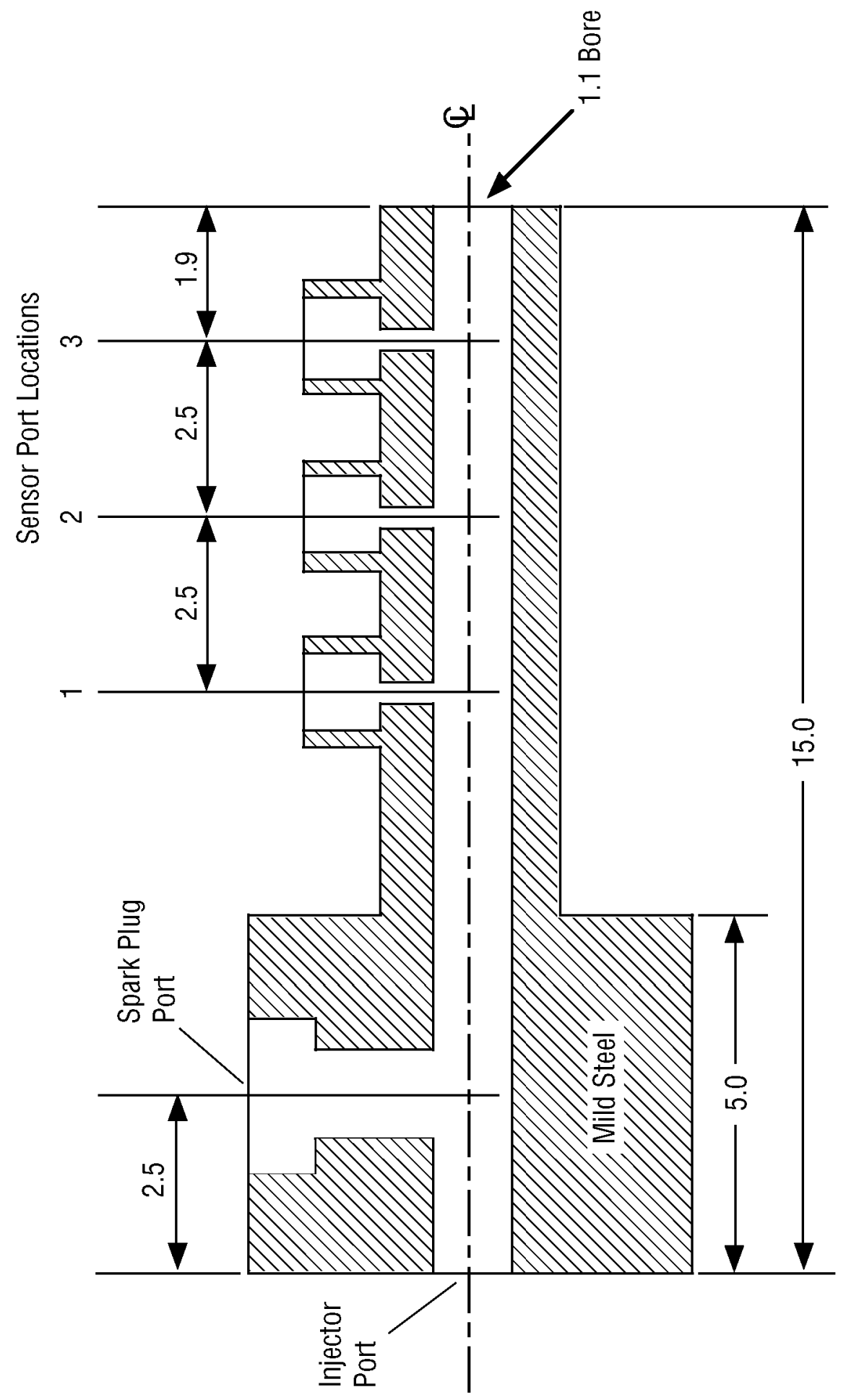

Figure 9. Cross section of the mild steel initiator model with pressure sensor ports (dimensions in centimeters). 


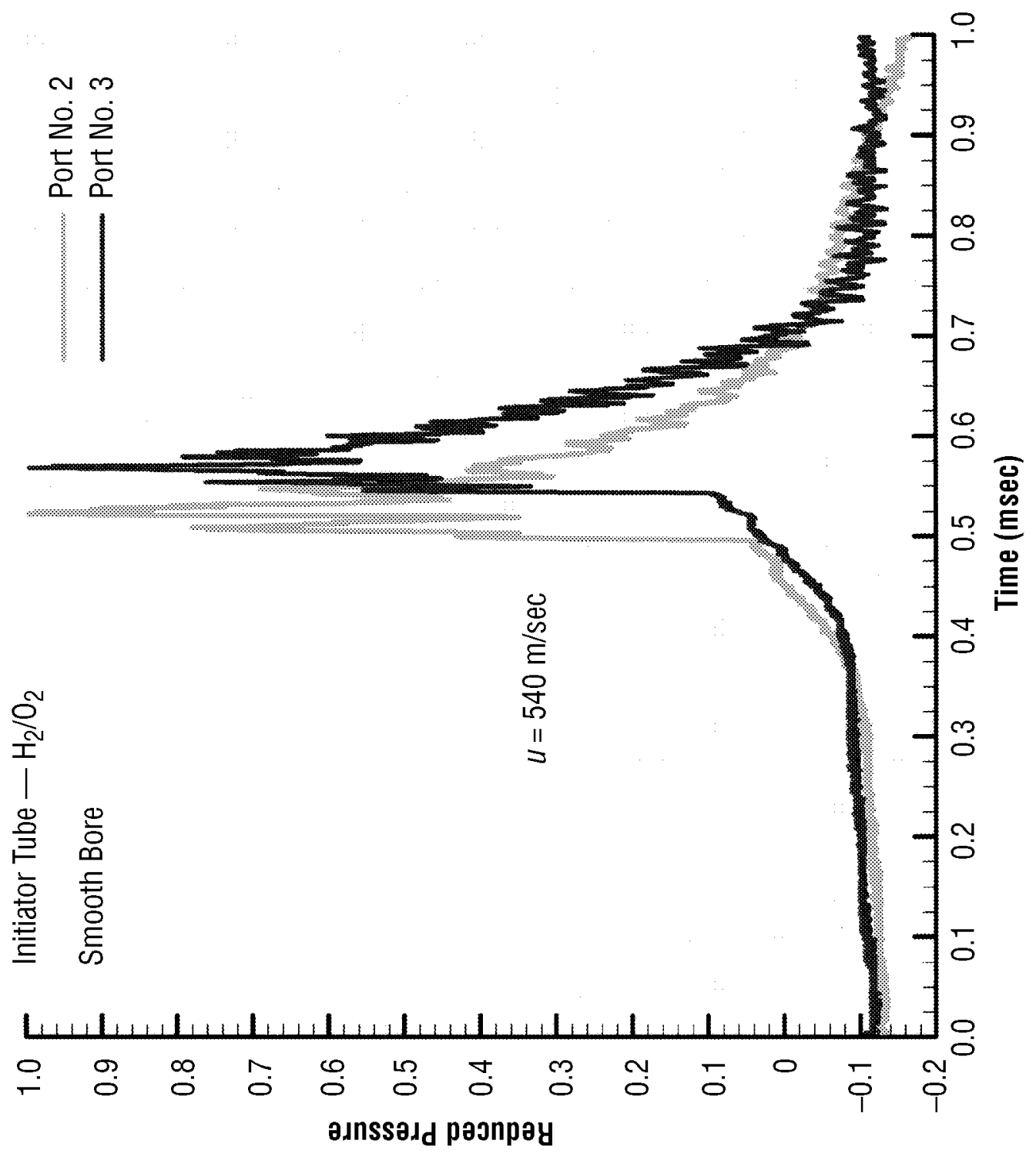

Figure 10. Measured pressure waveforms in the initiator tube with smooth bore. Indicated flame front velocity was $540 \mathrm{~m} / \mathrm{sec}$. 


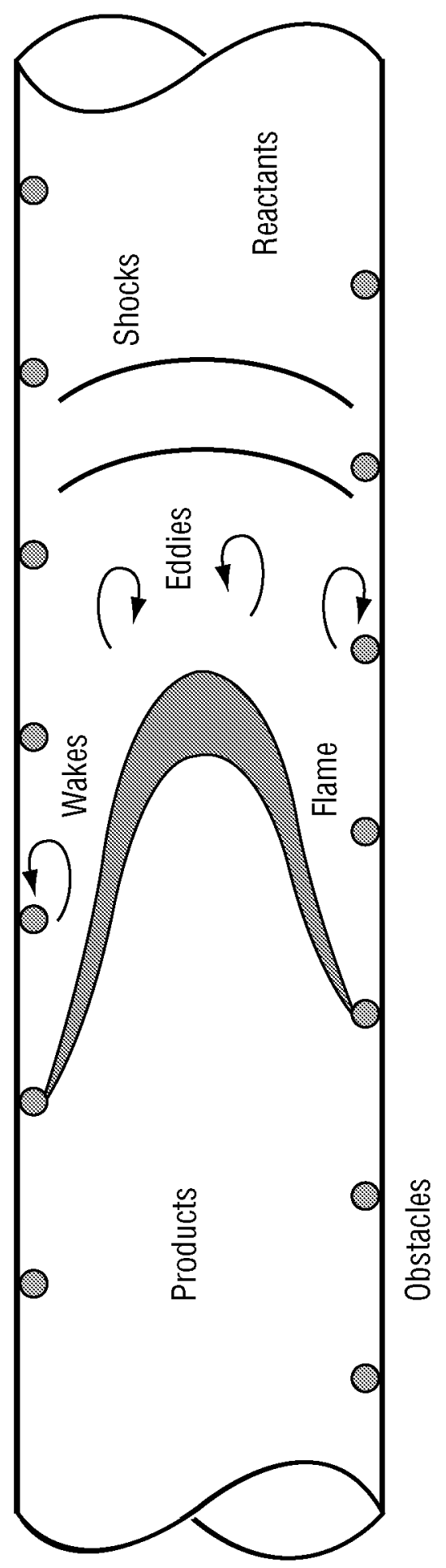

Figure 11. Illustration of Schelkin spiral and its effect on turbulent mixing and flame acceleration. 


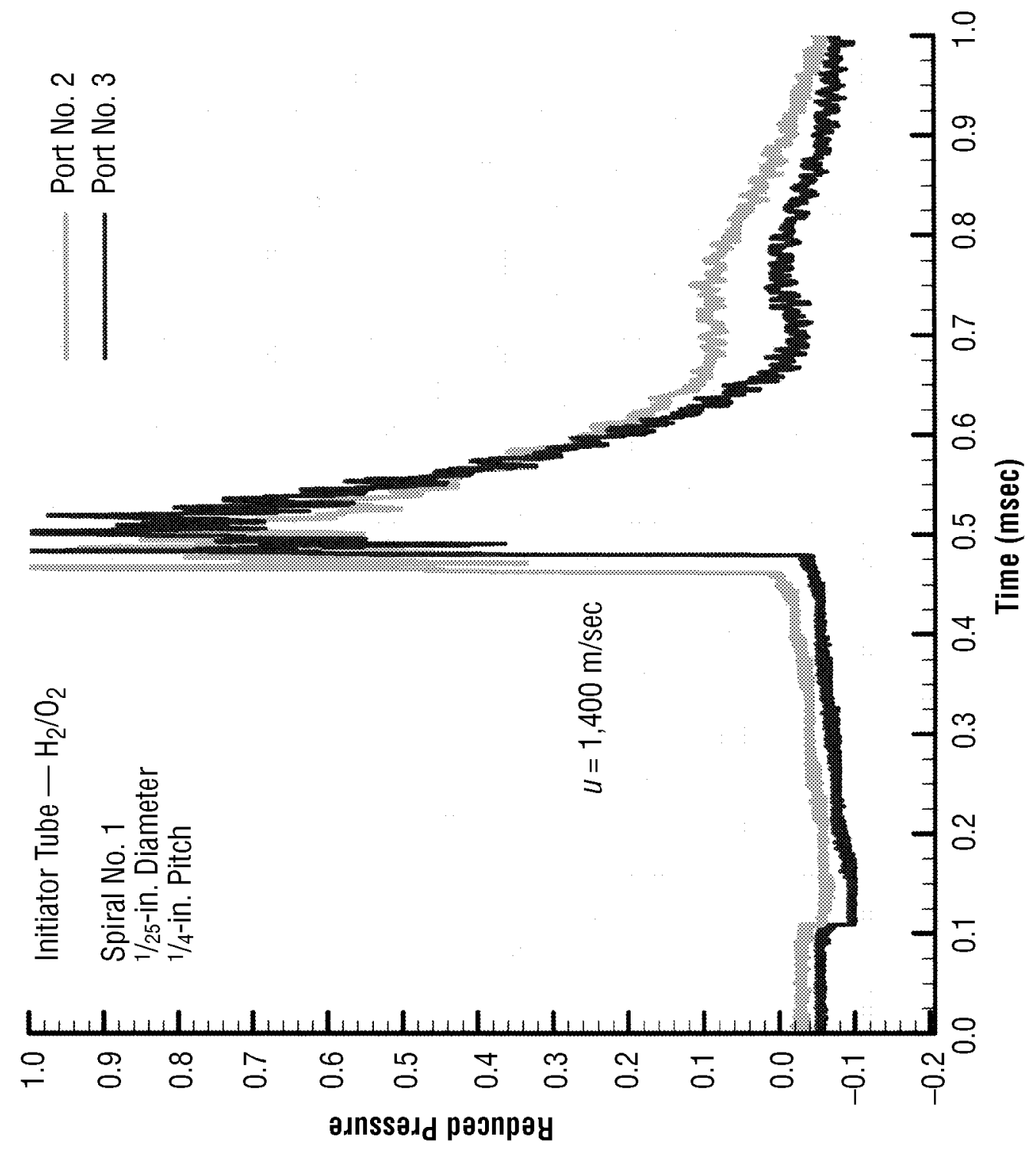

Figure 12. Measured pressure waveforms in the initiator tube with Schelkin spiral No. 1. Indicated flame front velocity was $1,400 \mathrm{~m} / \mathrm{sec}$. 


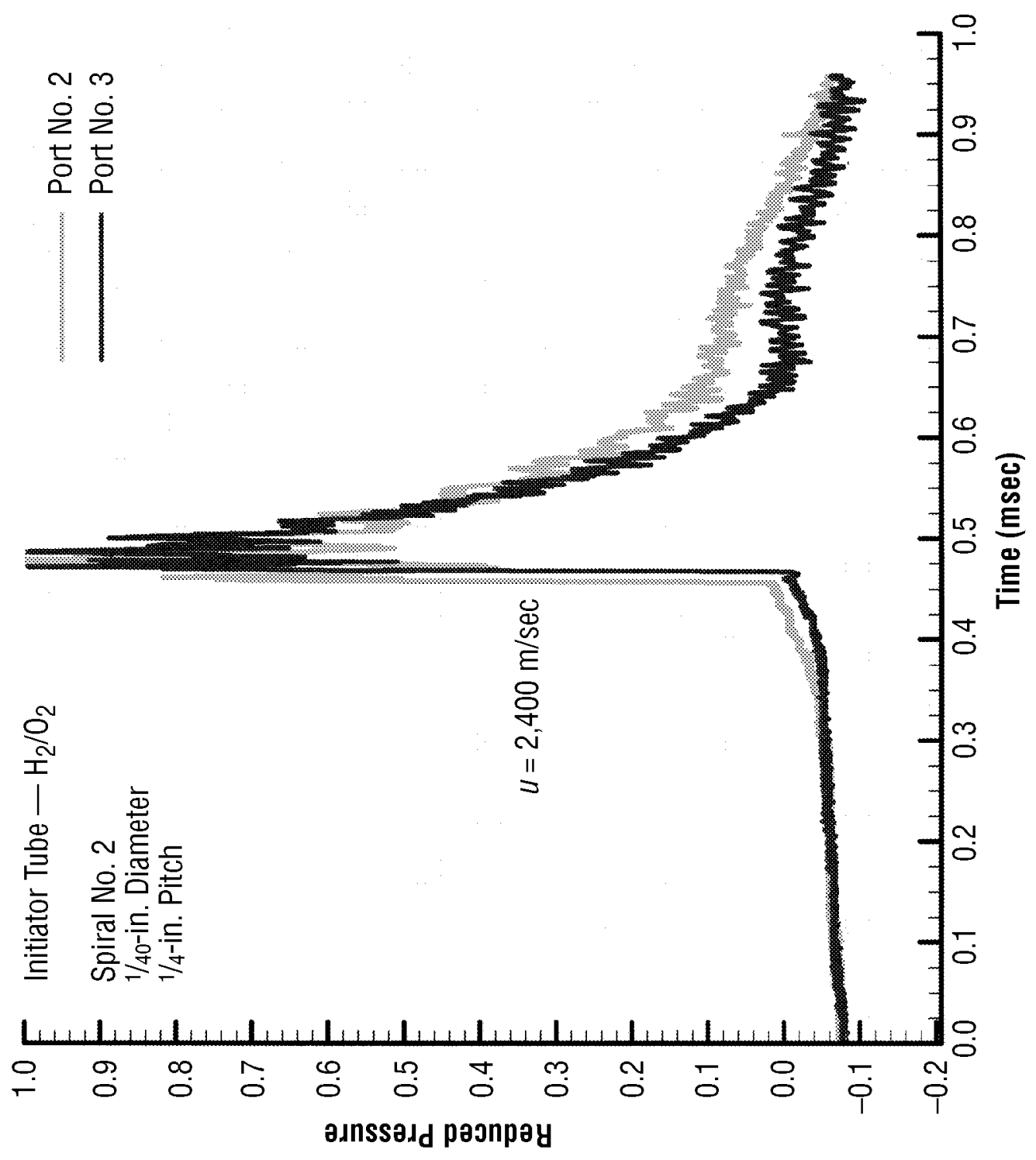

Figure 13. Measured pressure waveforms in the initiator tube with Schelkin spiral No. 2. Indicated flame front velocity was $2,400 \mathrm{~m} / \mathrm{sec}$. 


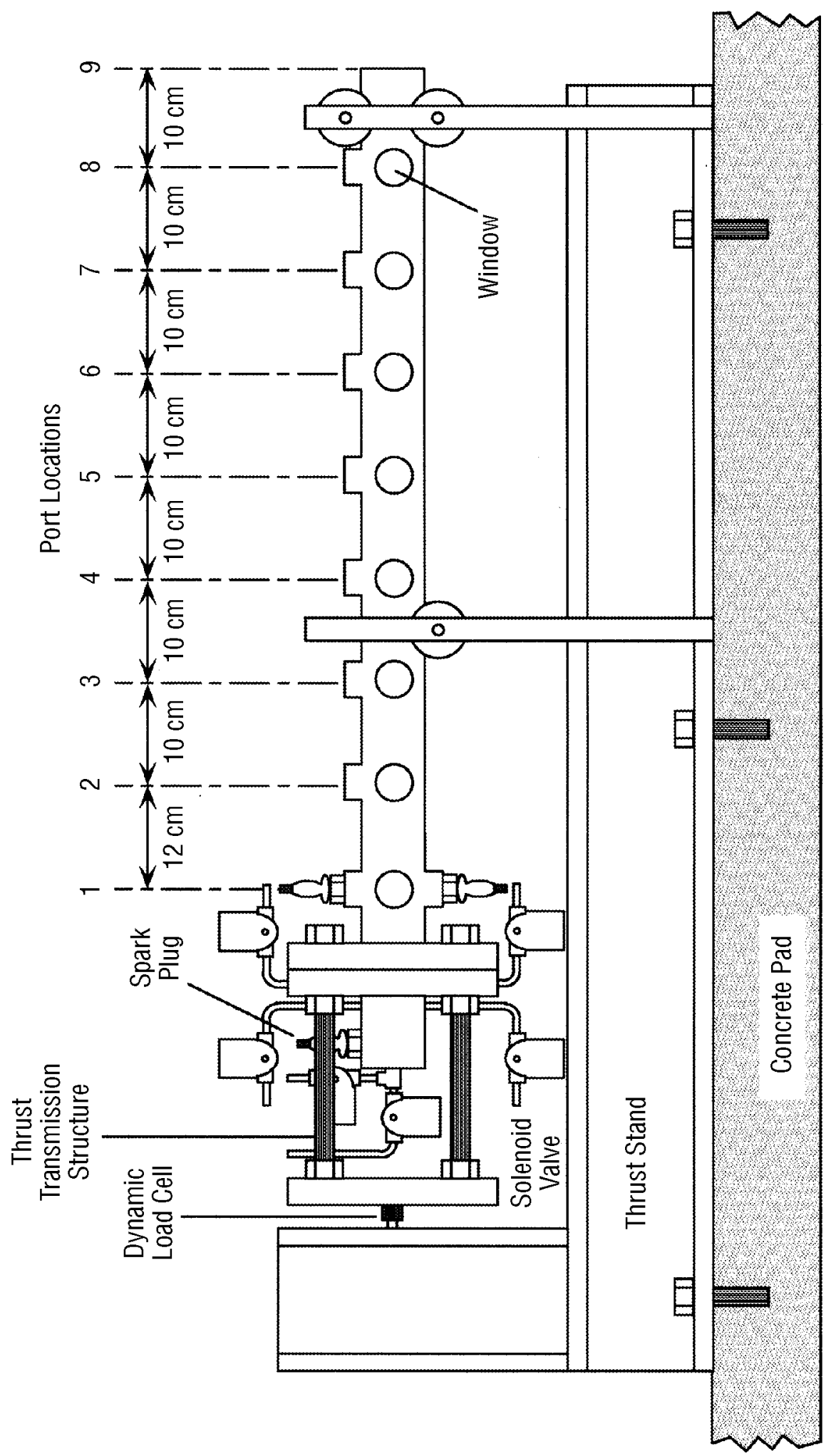

Figure 14. Schematic of PDRE-G-1 research engine on the test stand. Sensor port locations and indices are indicated. 


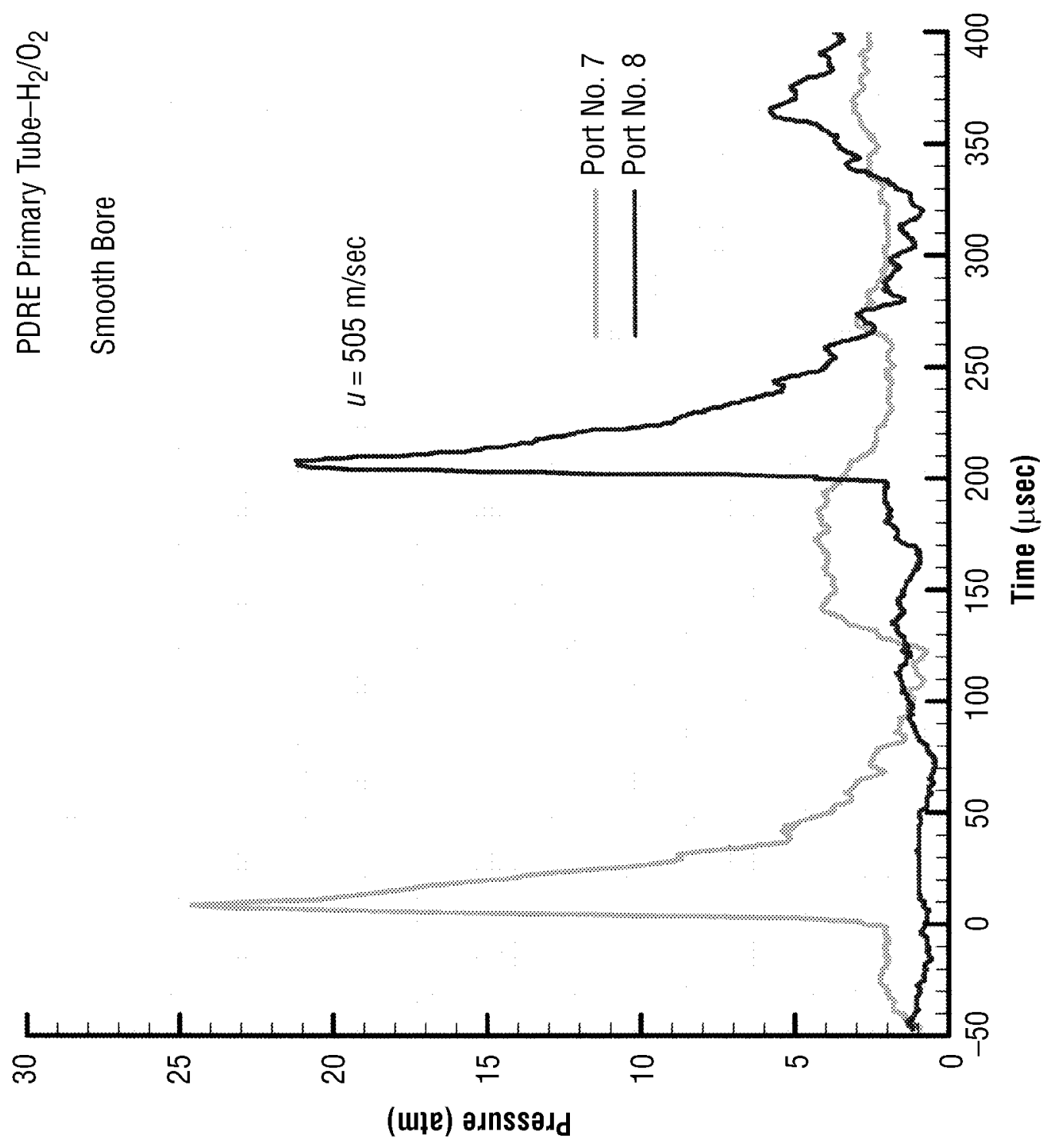

Figure 15. Measured pressure waveforms in the primary tube with smooth bore. Indicated flame front velocity was $505 \mathrm{~m} / \mathrm{sec}$. 


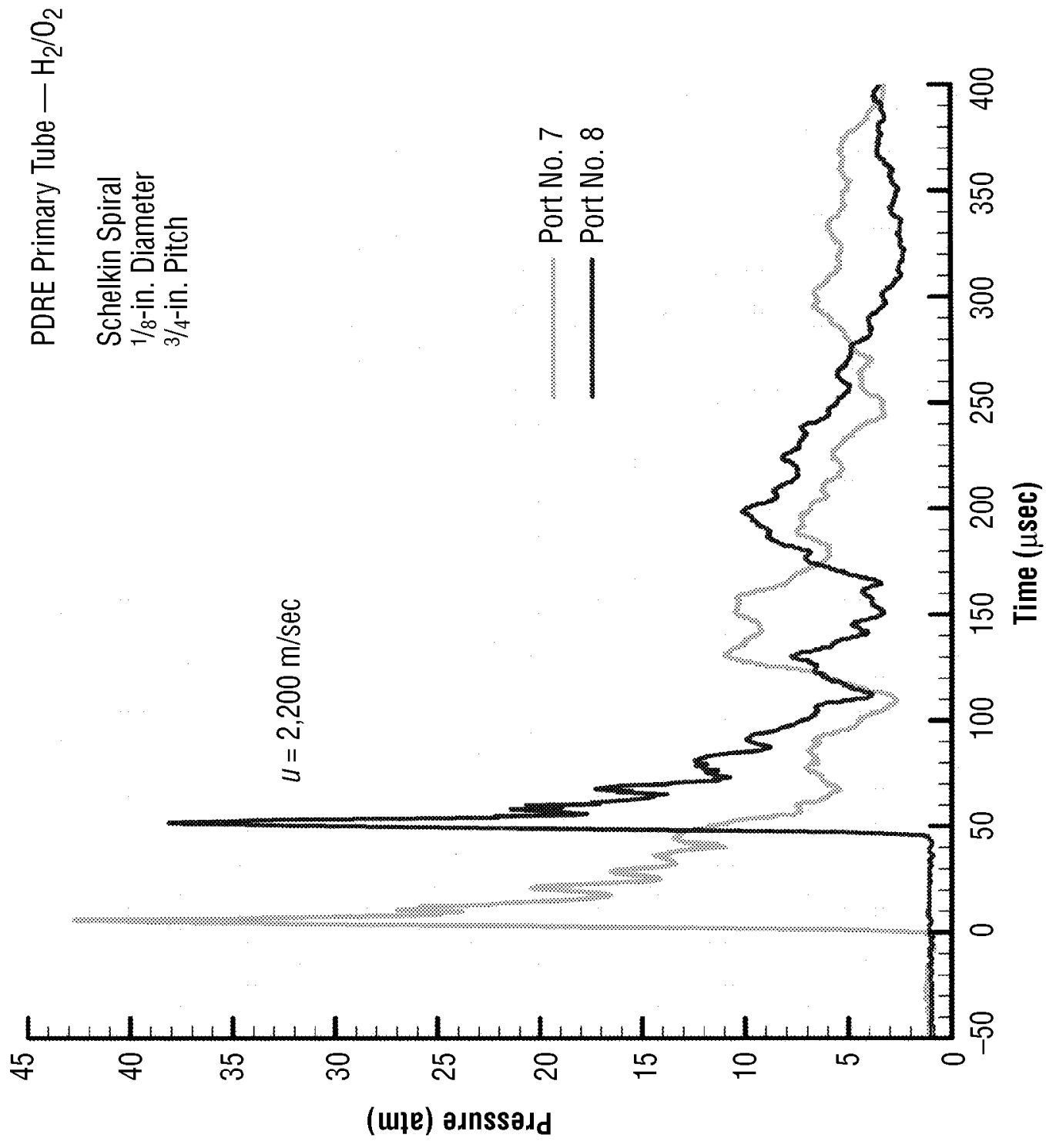

Figure 16. Measured pressure waveforms in the primary tube with Schelkin spiral installed along its entire length. Indicated flame front velocity was $2,200 \mathrm{~m} / \mathrm{sec}$. 


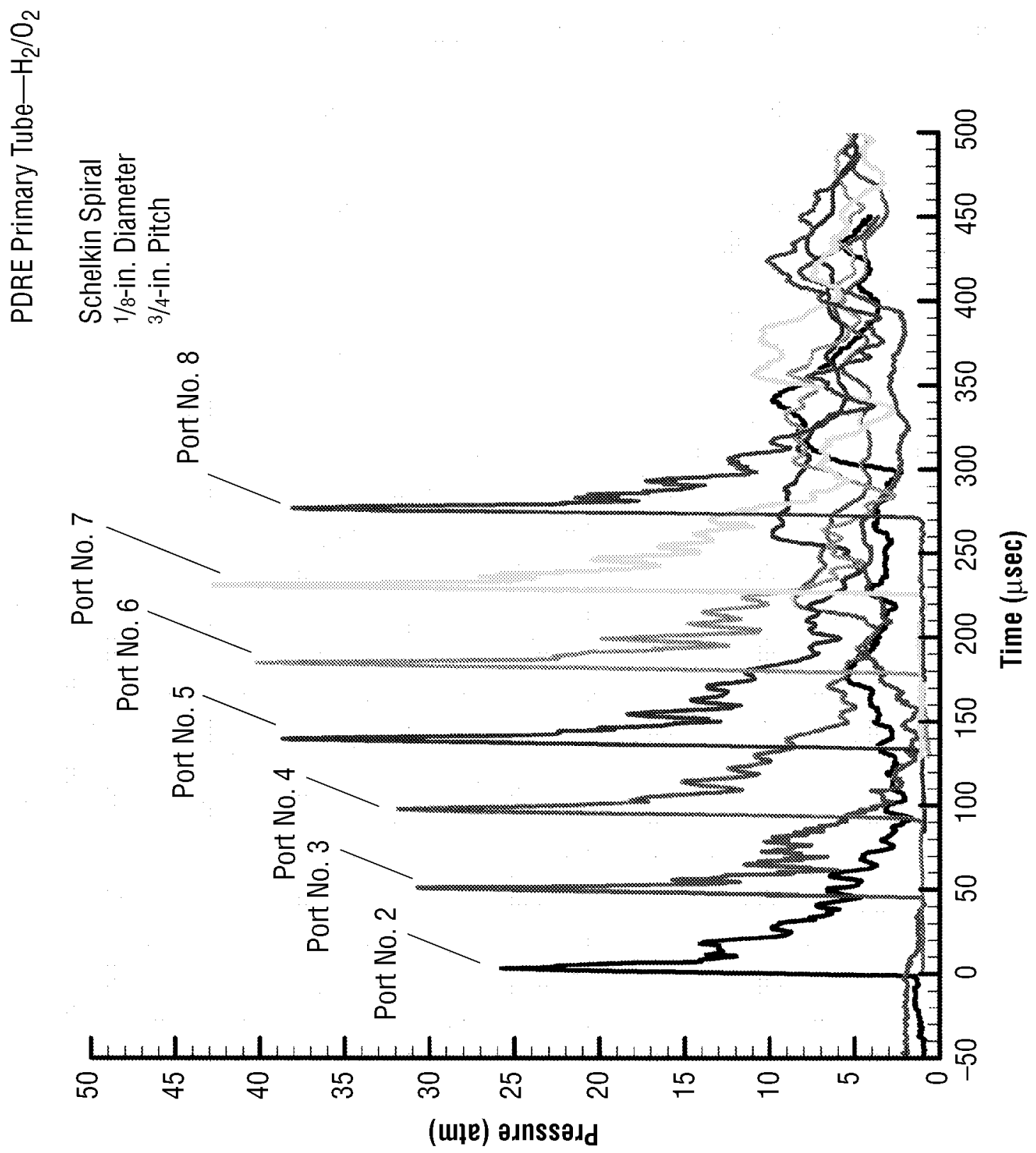

Figure 17. Measured pressure waveform distribution in the primary tube with Schelkin spiral installed along its entire length. 

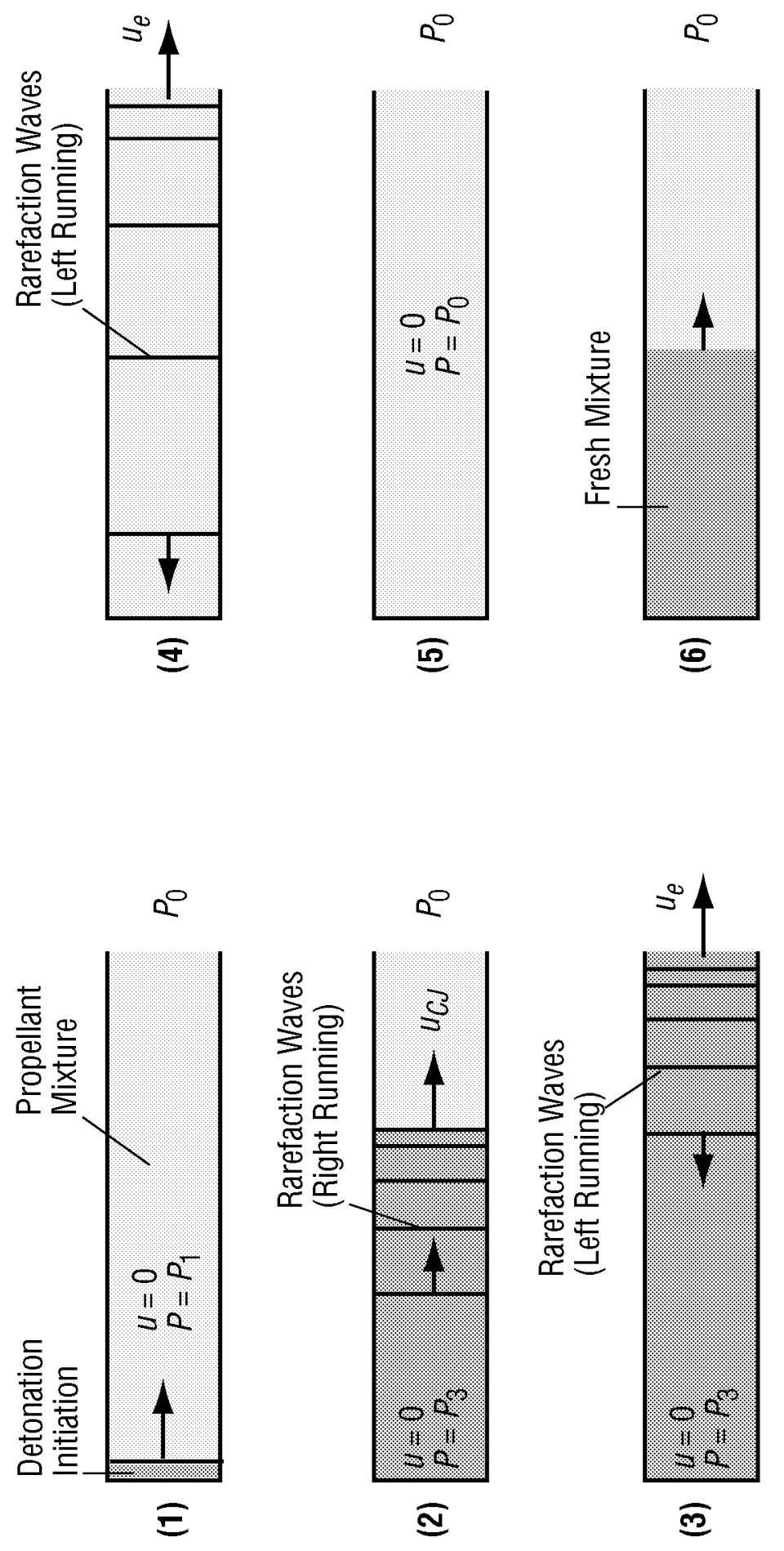

Figure 18. Idealized PDRE cycle processes: (1) Detonation initiation, (2) propagation of detonation wave through chamber, (3) propagation of rarefaction wave from tube exit to tube head, (4) tube blowdown, (5) chamber exhausted to atmospheric pressure, and (6) injection of fresh propellant mixture. 


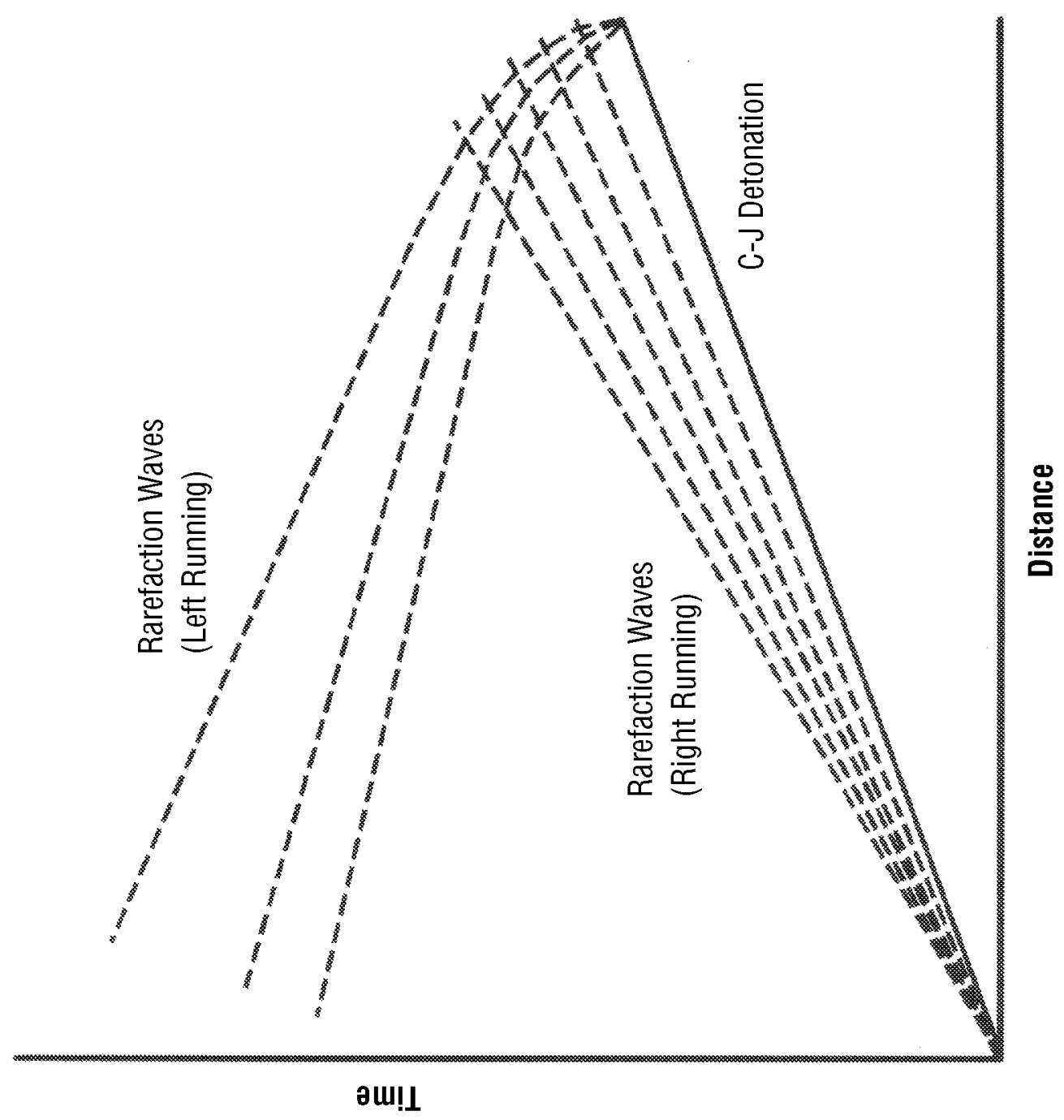

Figure 19. Idealized position-time wave diagram for PDRE blowdown process. 


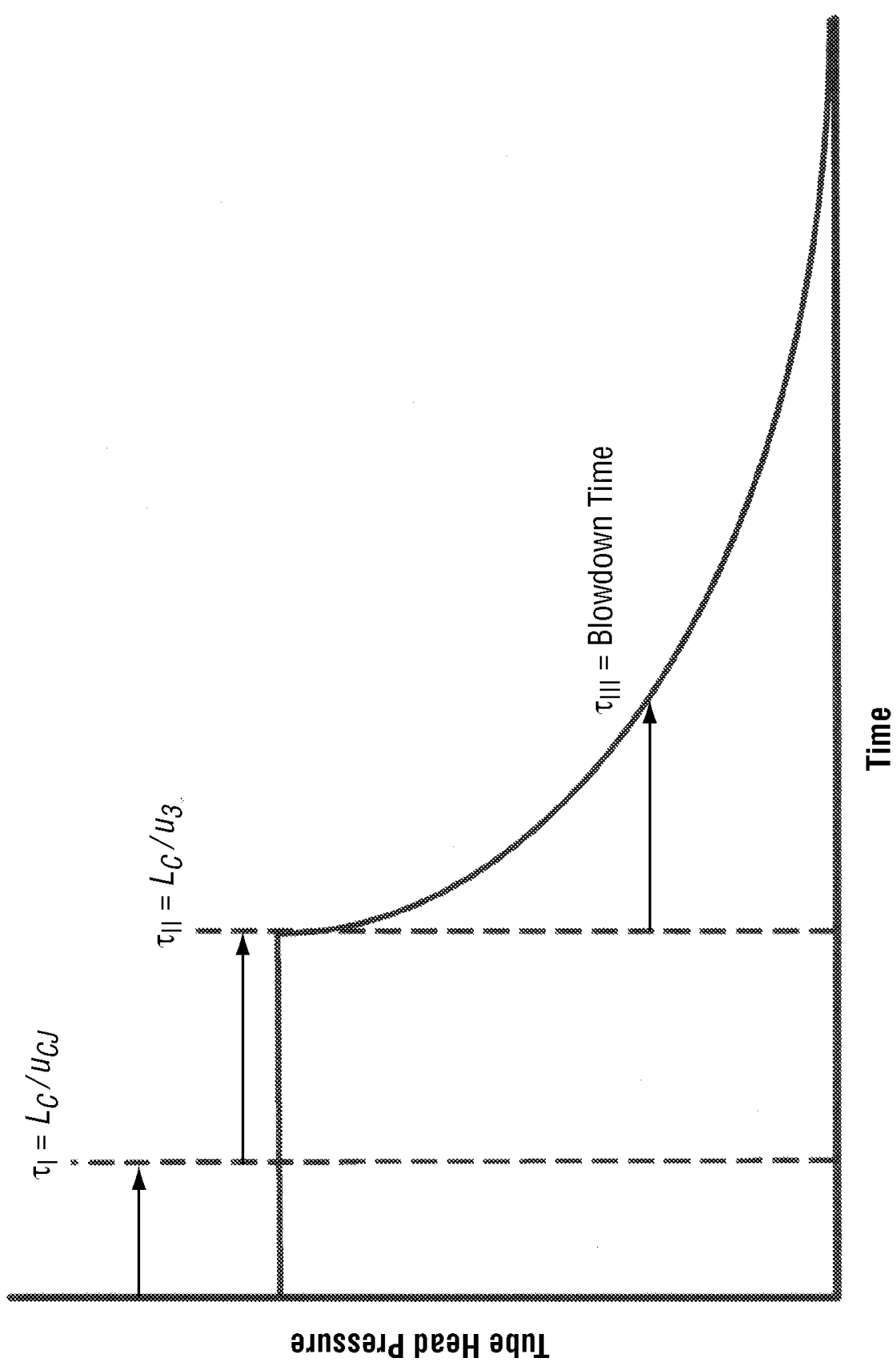

Figure 20. Idealized PDRE tube head pressure for a simple straight tube configuration. 


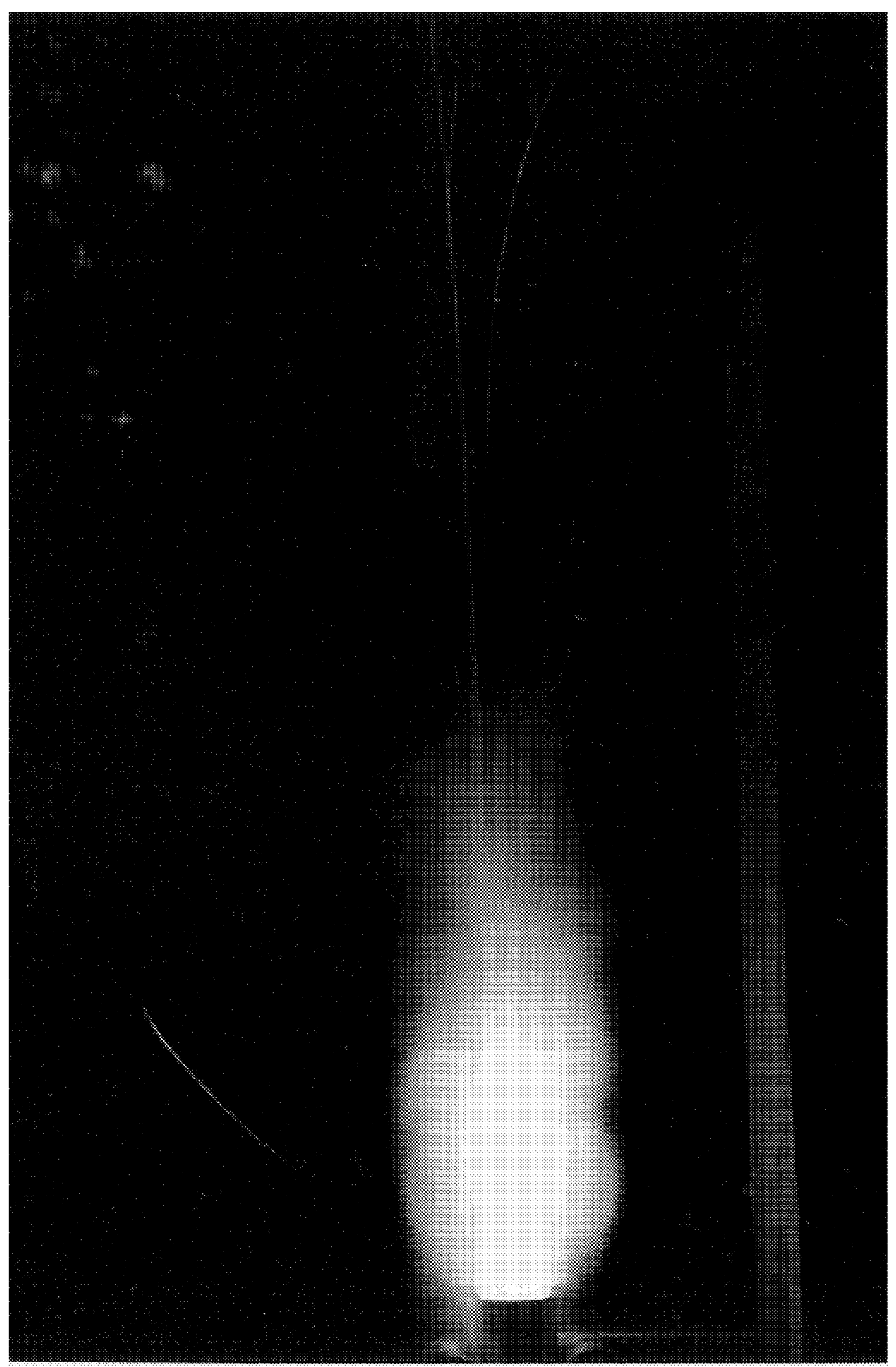

Figure 21. Long exposure photograph of the exhaust plume from the PDRE-G-1 engine illustrating the firing characteristics for a filled tube condition. Obtained during a night firing with hydrogen/oxygen propellants. 


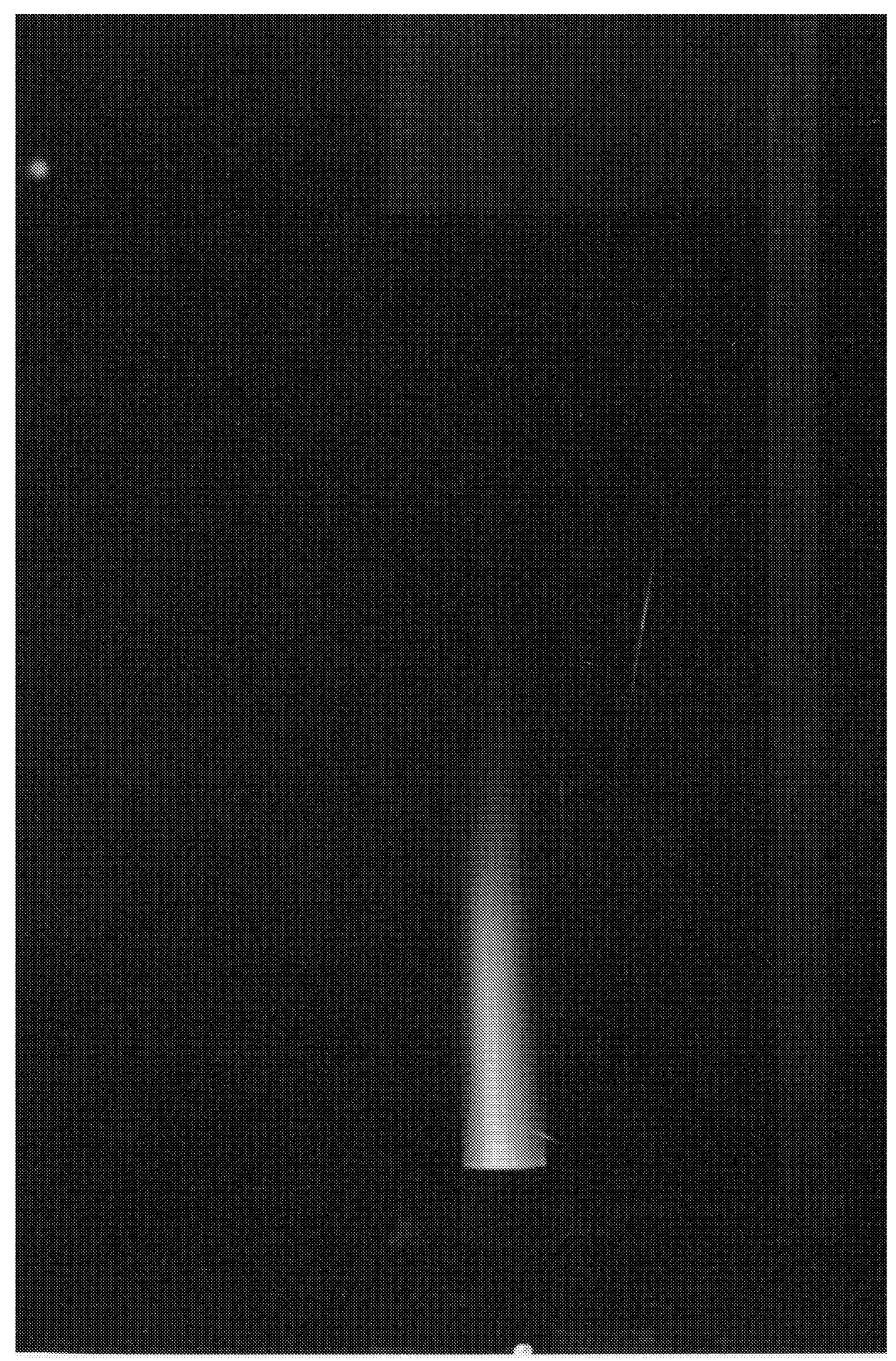

Figure 22. Long exposure photograph of the exhaust plume from the PDRE-G-1 engine illustrating the firing characteristics for an underfilled tube condition. Obtained during a night firing with hydrogen/oxygen propellants. 


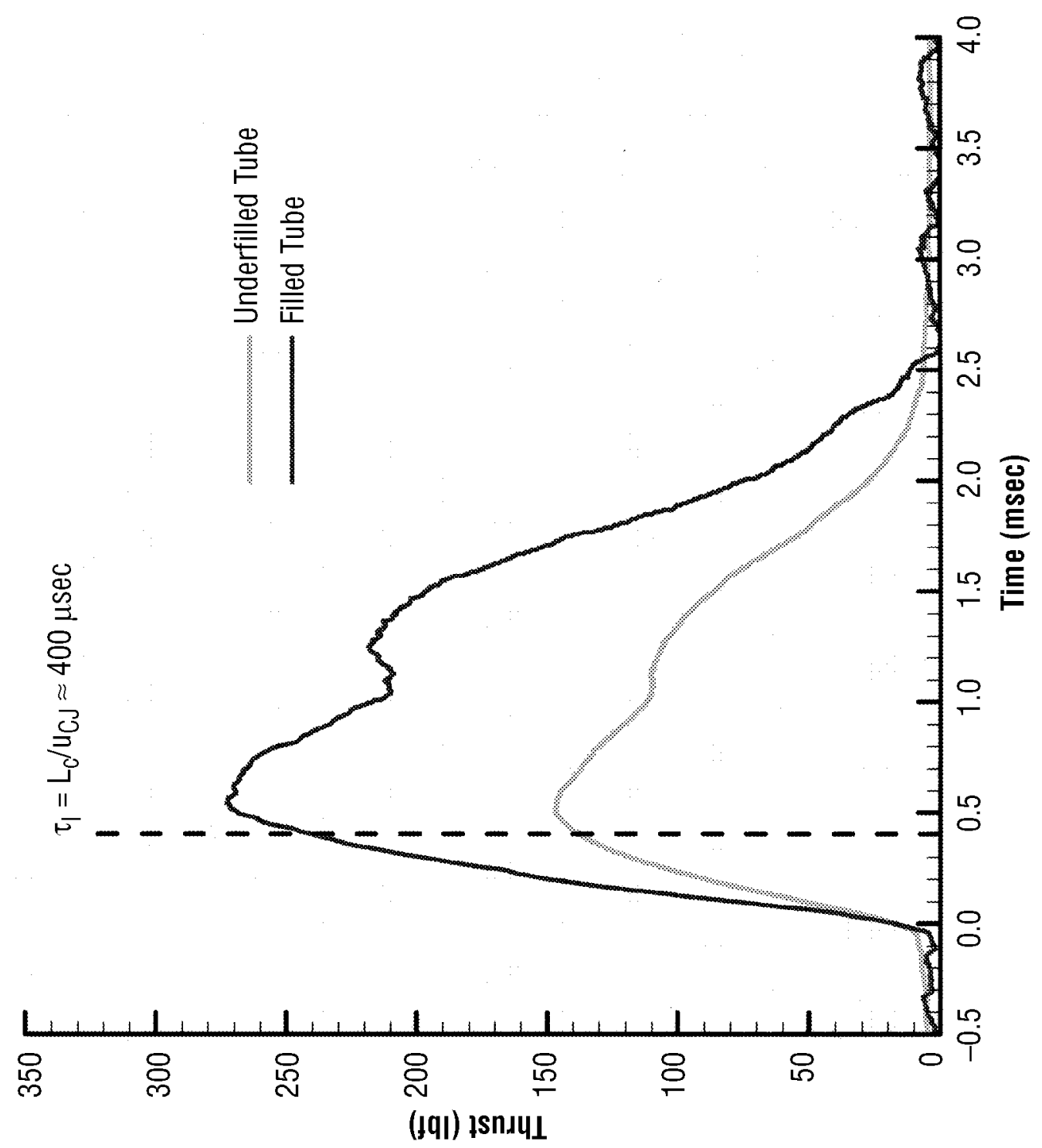

Figure 23. Time-resolved PDRE-G-1 engine thrust profiles for filled and underfilled tube conditions. 


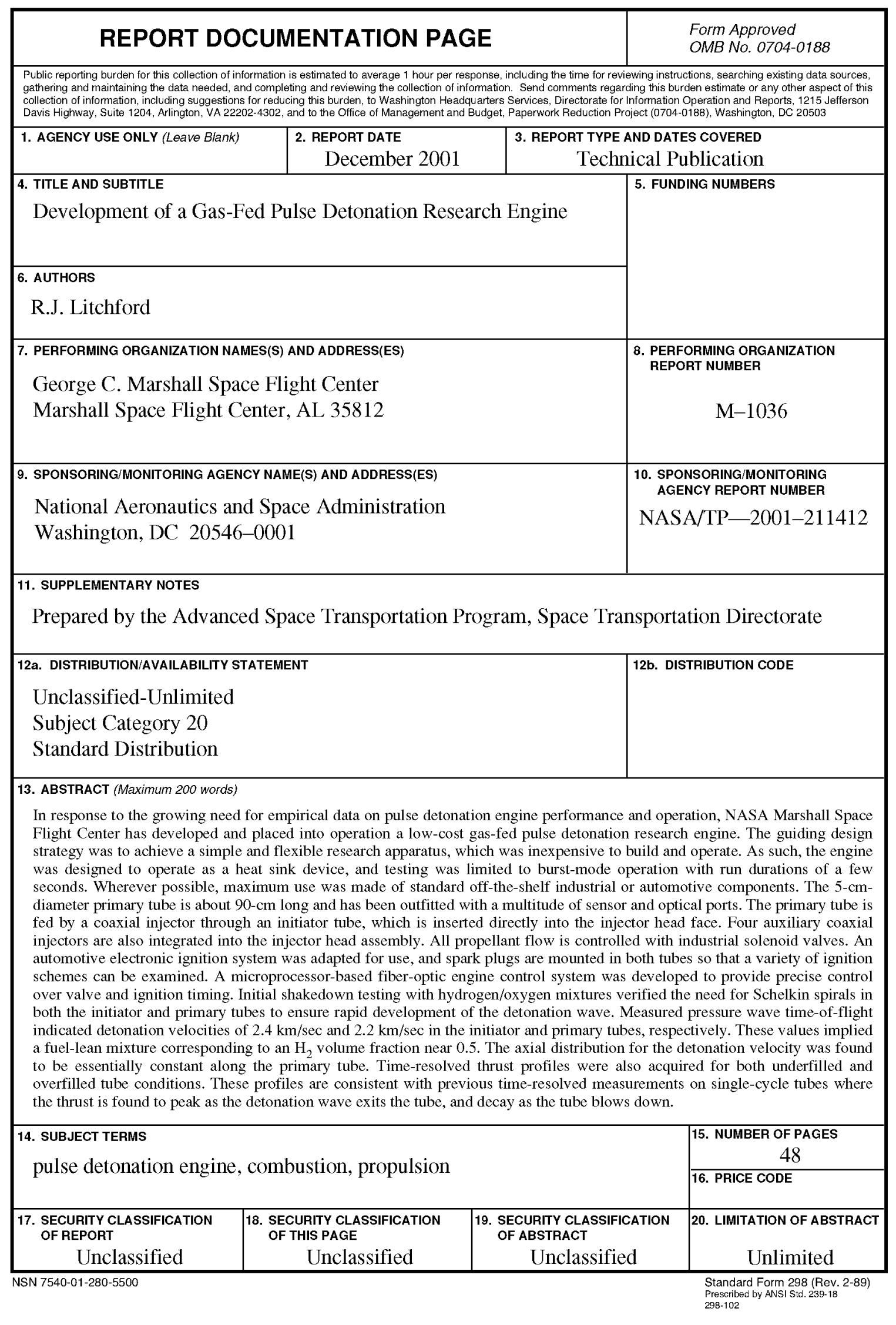

